\title{
Neurotrimin Mediates Bifunctional Effects on Neurite Outgrowth via Homophilic and Heterophilic Interactions
}

\author{
Orlando D. Gil,, ${ }^{1}$ George Zanazzi, ${ }^{1}$ Arie F. Struyk, ${ }^{1}$ and James L. Salzer ${ }^{1,2}$ \\ Departments of ${ }^{1}$ Cell Biology and ${ }^{2}$ Neurology, New York University Medical School, New York, New York 10016
}

Neurotrimin (Ntm) together with the limbic system-associated membrane protein (LAMP) and the opioid-binding cell adhesion molecule (OBCAM) comprise the IgLON family of neural cell adhesion molecules. These glycosylphosphatidylinositol (GPI)anchored proteins are expressed in distinct neuronal systems. In the case of Ntm, its expression pattern suggests a role in the development of thalamocortical and pontocerebellar projections (Struyk et al., 1995). We have now characterized Ntm's function in cell adhesion and in neurite outgrowth. Cross-linking studies of transfected cells show that Ntm forms noncovalent homodimers and multimers at the cell surface. Ntm mediates homophilic adhesion, as evidenced by the reaggregation of the transfected cells and the specific binding of an Ntm-Fc chimera to these cells. Consistent with these results, Ntm-Fc binds to neurons that express Ntm at high levels, e.g., dorsal root gan- glion (DRG) and hippocampal neurons. It does not bind to DRG neurons treated with phosphatidylinositol-specific phospholipase C (PI-PLC) or to sympathetic neurons that do not express $\mathrm{Ntm}$ or other members of the IgLON family at significant levels. $\mathrm{Ntm}$ promotes the outgrowth of DRG neurons, even after PIPLC treatment, suggesting that its effects on outgrowth are mediated by heterophilic interactions. Of particular note, both membrane-bound and soluble $\mathrm{Ntm}$ inhibit the outgrowth of sympathetic neurons. These results strongly suggest that $\mathrm{Ntm}$, and other members of the IgLON family, regulate the development of neuronal projections via attractive and repulsive mechanisms that are cell type specific and are mediated by homophilic and heterophilic interactions.

Key words: neurotrimin; IgLON family; neurite outgrowth; homophilic adhesion; repulsion; GPI-anchored
During development, a wide variety of membrane-associated and soluble proteins direct growing axons toward their targets via growth-promoting and -inhibiting effects (Tessier-Lavigne and Goodman, 1996). Proteins that largely promote neurite outgrowth include cell adhesion molecules (CAMs) of the Ig (Salzer and Colman, 1989; Brümmendorf and Rathjen, 1993), cadherin (Matsunaga et al., 1988; Bixby and Harris, 1991) and integrin (Reichardt and Tomaselli, 1991) superfamilies. More recently, molecules that inhibit neurite outgrowth during axonal pathfinding have been identified. These include the ephrins (Drescher et al., 1997), the semaphorins (Kolodkin et al., 1993; Luo et al., 1993), and the netrins, which promote or inhibit outgrowth in a cell type-specific manner (Serafini et al., 1994; Colamarino and Tessier-Lavigne, 1995).

Members of the Ig superfamily have a major role in regulating neurite outgrowth. Molecules such as NCAM and L1 are widely expressed and promote the outgrowth of most neurons (Rutishauser, 1993). Other IgCAMs, such as TAG-1 (Dodd et al., 1988), have a restricted expression pattern and are likely to provide specific guidance cues required for correct targeting.

Received March 11, 1998; revised July 10, 1998; accepted Aug. 26, 1998.

This work was supported by National Institutes of Health Grant NS33165 to J.L.S. We thank Dr. C. Stanners for CHO cell line LR73, Dr. P. Crocker for the pIG vector and MUC18-pIG construct, Drs. M. Grumet and T. Sakurai for CHO cells expressing a GPI-anchored form of NgCAM, Dr. F. Giancotti for fibronectin, Dr. G. Wilkin for antibodies to GAP-43, Dr. T. Jessell for neurofilament antibody 3A10, Drs. D. Friedlander and D. Felsenfeld for advice on adhesion and neurite outgrowth assays, L. Brookhouse-Gil for assistance with graphics, and Dr. G. Fishell for the use of his imaging facilities.

Correspondence should be addressed to Dr. James L. Salzer, Department of Cell Biology, New York University Medical School, 550 First Avenue, New York, NY 10016.

Dr. Struyk's present address: Department of Neurology, Massachusetts General Hospital, Harvard Medical School, Cambridge, MA 02115.

Copyright (C) 1998 Society for Neuroscience $\quad 0270-6474 / 98 / 189312-14 \$ 05.00 / 0$
Notable among the IgCAMs with a restricted distribution are the limbic system-associated membrane protein (LAMP), the opioidbinding cell adhesion molecule (OBCAM), and neurotrimin (Ntm) (Schofield et al., 1989; Pimenta et al., 1995; Struyk et al., 1995), which together comprise the IgLON family. On the basis of genomic Southern blots, additional members of the family may exist (Struyk et al., 1995) but have yet to be identified. Each of these proteins has three Ig-like domains, exhibits significant sequence homology, and is attached to the membrane by a glycosylphosphatidylinositol (GPI)-anchor. Together they represent the earliest and most abundant GPI-anchored proteins expressed by neurons (Salzer et al., 1996).

Individual members of the $\operatorname{IgLON}$ family are expressed on distinct populations of neurons that, for the most part, form functional circuits. Thus LAMP is expressed by cortical and subcortical neurons of the limbic system (Levitt, 1984) and has been strongly implicated in the development of projections in this system (Pimenta et al., 1995; Zhukareva and Levitt, 1995). Ntm has an expression pattern that is largely complementary to that of LAMP, with highest expression in the sensorimotor cortex, for example. Its expression in layers IV, V, and VI of the cortex, the subplate, and the rostral lateral thalamus as well as in the pontine nucleus and cerebellum suggests a potential role in the development of thalamocortical and pontocerebellar projections, respectively (Struyk et al., 1995). OBCAM has a much more restricted distribution, with highest expression in the cortical plate and hippocampus (Struyk et al., 1995).

In this report, we have characterized the function of $\mathrm{Ntm}$ in neurite outgrowth and cell adhesion. We provide evidence that Ntm forms noncovalent homodimers in the plane of the membrane, promotes adhesion by a homophilic mechanism, and regulates neurite outgrowth. Of note, Ntm has opposing effects on 
the outgrowth of sensory neurons (which express Ntm) and sympathetic neurons (which do not), promoting and inhibiting their outgrowth, respectively. Ntm mediates these dual effects on neurite outgrowth as both a membrane-bound and a soluble molecule. These results further support a role for Ntm in the formation of specific neuronal projections and suggest a broader mechanism of action for members of the IgLON family that involves homophilic and heterophilic modulation of neurite outgrowth.

\section{MATERIALS AND METHODS}

Construction and expression of a myc-tagged Ntm. A c-myc epitope tag (EQKLISEEDL) was added between the third Ig-like domain of Ntm and the site of GPI attachment (i.e., between amino acids 323 and 324 of rat Ntm) by the "patch" PCR method (Squinto et al., 1990). The plasmid pBSK-392B containing the complete coding region of neurotrimin (Struyk et al., 1995) was used as a template. Primers included a $3^{\prime}$ vector-specific oligonucleotide, a $5^{\prime}$ primer (5'-GCGCGTCAACGAG CAAAAGCTTATTTCTGAGGAGGATCTG-3'), and the "patch" primer (5'-ATTTCTGAGGAGGATCTGAATGGGACGTCAAGGAGG$\left.3^{\prime}\right)$. This resultant PCR product was gel-purified and religated back into the HinC II site of the neurotrimin coding sequence in pBSK-392B. The modified Ntm cDNA was verified by sequencing and subcloned into the eukaryotic expression vector pRC-CMV (Invitrogen, San Diego, CA). The final Ntm-pRC construct was introduced into the Chinese Hamster Ovary (CHO) cell line LR73 (Pollard and Stanners, 1979) by Lipofection, following the manufacturer's instructions (Life Technologies, Gaithersburg, MD). Transfected cells were selected with $800 \mu \mathrm{g} / \mathrm{ml}$ and maintained with $400 \mu \mathrm{g} / \mathrm{ml}$ of G418 (Life Technologies); multiple colonies of transfected cells were pooled and expanded. CHO-Ntm expressors were isolated from pooled cells by fluorescence-activated cell sorting (FACS) after staining with a monoclonal antibody specific for the c-myc decapeptide tag (Evan et al., 1985) and fluorescein-conjugated donkey anti-mouse IgG antiserum (Chemicon, Temecula, CA). Expressors were expanded and subsequently subjected to a second round of FACS. The two populations of cells, i.e., those sorted one or two times, will be referred to as low expressor (LE) and high expressor (HE) cells, respectively. Control CHO-CMV cells were generated by pooling multiple clones transfected with the pRC-CMV plasmid alone.

Characterization of Ntm expression in $\mathrm{CHO}$ cells. In some experiments, transfected cell lines were surface-biotinylated by incubation of cell monolayers with NHS-sulfo-biotin (Pierce, Rockford, IL) as described previously (Rosen et al., 1992) to facilitate subsequent identification of the myc-tagged neurotrimin. Monolayers were lysed with $1 \%$ SDS in 20 mm Tris, pH 7.4, $6 \mathrm{~mm} \mathrm{NaCl}$, and $15 \mathrm{~mm}$ DTT. After they were boiled, lysates were diluted in $3 \mathrm{vol}$ of $2.5 \%$ Triton X-100, $50 \mathrm{~mm}$ Tris, pH 7.4, $190 \mathrm{~mm} \mathrm{NaCl}$, and $6 \mathrm{~mm}$ EDTA and incubated with anti-myc ascites (containing $\sim 5 \mu \mathrm{g}$ of $\mathrm{IgG}$ ), and immune complexes were collected with protein G-coupled Sepharose (Pharmacia Biotech, Piscataway, NJ). Precipitated proteins were separated by SDS-PAGE and electroblotted onto nitrocellulose. Blots were probed with streptavidin conjugated to alkaline phosphatase and incubated with 5-bromo-4-chloro-3-indolyl-phosphate/ nitroblue tetrazolium (BCIP-NTP; Kirkegaard and Perry Laboratories, Gaithersburg, MD).

To confirm that the neurotrimin expressed by the CHO-Ntm was indeed GPI-anchored, monolayers were incubated with PI-PLC (Oxford Glycosystems, Rosedale, NY) at a concentration of $1 \mathrm{U} / \mathrm{ml}$ for $1 \mathrm{hr}$ at $37^{\circ} \mathrm{C}$ in PBS containing protease inhibitors (PMSF, aprotinin, and leupeptin, all at a concentration of $0.1 \%$ ). Supernatants were collected and precipitated by the addition of 0.01 vol of $2 \%$ deoxycholic acid and 0.10 vol of TCA. Cell lysates and precipitated proteins from culture supernatants were fractionated by SDS-PAGE, electroblotted, and probed with the anti-myc antibody.

Cross-linking analysis of Ntm. CHO cell-surface proteins were crosslinked by incubating monolayers with the homobif unctional reagent Bis (sulfosuccinimidyl) suberate $\left(\mathrm{BS}^{3}\right)$ (Pierce) at a concentration of 0.25 $\mathrm{mm}$ for $20 \mathrm{~min}$, followed by a $10 \mathrm{~min}$ incubation with Leibovitz's L-15 media (Life Technologies) to stop the reaction. After three washes in PBS, monolayers were biotinylated, and Ntm was immunoprecipitated with the anti-myc monoclonal antibody as described above. In some cases, cross-linking was followed by a $1 \mathrm{hr}$ incubation with PI-PLC to determine whether the cross-linked products were GPI-anchored. Immunoprecipitates were then prepared from the cell lysates and supernatants.
The effect of cell density on the cross-linking of neurotrimin was investigated by plating $1 \times 10^{5}$ cells on either 35,60 , or $100 \mathrm{~mm}$ tissue culture dishes. After $24 \mathrm{hr}$ of growth, cell-surface proteins were cross-linked and immunoprecipitated as above.

Aggregation assays. Subconfluent monolayers of CHO-Ntm or CHOCMV cells were dissociated in HBSS (Life Technologies) with $0.02 \%$ EDTA and $0.0025 \%$ trypsin (Life Technologies) by multiple rounds of trituration and resuspended in L-15 media with ITs + (Becton Dickinson Labware, Franklin Lakes, NJ), $10 \mu \mathrm{M}$ DNase, and $1 \mu \mathrm{M}$ EDTA. Cell density was standardized in each experiment to a final concentration of $1 \times 10^{6}$ cells $/ \mathrm{ml}$. Cell suspensions were then incubated in $5 \% \mathrm{CO}_{2}$ at $37^{\circ} \mathrm{C}$. At defined time points, aliquots were removed by a wide-bore pipette, and single cells were counted with a hemocytometer. In some experiments, CHO-Ntm cells were pretreated with PI-PLC $(1 \mathrm{U} / \mathrm{ml})$ in L-15-ITs + for $1 \mathrm{hr}$ as described above. To determine whether the adhesion was homophilic or heterophilic, aggregates were analyzed after mixing CHO-Ntm cells prelabeled with the carbocyanine dye diI (Molecular Probes, Eugene, OR) with control cells prelabeled with diO (Molecular Probes). As a further control, diI-prelabeled CHO-Ntm cells were mixed with diO-prelabeled $\mathrm{CHO}-\mathrm{Ntm}$ cells.

Generation of Ntm-Fc chimera. To generate a soluble Ntm chimeric protein, the three Ig domains of Ntm were fused to a human Fc segment encoded by the pIG vector (Simmons, 1993). To this end, the sequences encoding the GPI anchor as well as the $3^{\prime}$ untranslated region were deleted, and a new fragment, which contained a splice acceptor and a BamHI restriction site, was added. Specifically, the neurotrimin cDNA was amplified with primer 1 (which anneals to an oligonucleotide sequence corresponding to positions $918-935$ of the Ntm cDNA) and primer 2 (which anneals to an oligonucleotide sequence corresponding to nucleotides 1428-1410): primer 1: 5'-CTC CAT TAA TGA AGG GAA3'; primer 2: 5'-ACGGAT CCA CTT ACC TGT GAC AGC ACC TGG GCC AAA TAGC $3^{\prime}$.

The amplified PCR product has a BamHI site, a splice donor site (underlined), and a sequence complementary to Ntm (1428-1410, $\left.5^{\prime} \rightarrow 3^{\prime}\right)$ on the $3^{\prime}$ side of primer 2 . The PCR product was digested with Bam HI and PstI, releasing a $241 \mathrm{bp}$ fragment. This fragment was ligated into a full-length Ntm cDNA in the pBluescript KS vector (Stratagene, La Jolla, CA) that had previously been digested with Bam HI and PstI. This modified Ntm cDNA, which lacks the GPI anchor and 3' noncoding regions, was excised with EcoRI and BamHI and subcloned into the pIG-1 vector, which had been digested with the same restriction enzymes. The construct, corresponding to the sequence encoding the ectodomain of Ntm subcloned into the pIG-1 vector, was transiently transfected into COS-1 cells by the DEAE-dextran method (Simmons, 1993). Transfected cells were incubated in DMEM with the supplement ITs + , and the media was collected after $5 \mathrm{~d}$. Ntm-Fc was purified by affinity chromatography with protein A Sepharose (Sigma, St. Louis, MO). After purification, protein concentration was assayed by the Micro BCA system (Pierce) and visualized on a $7.5 \%$ SDS polyacrylamide gel by Coomassie blue.

Primary neuronal cultures. Cultures of dorsal root ganglia (DRG) and superior cervical ganglia (SCG) neurons were established as described previously (Rosen et al., 1992). Briefly, DRGs were removed from embryonic day 16 rats under aseptic conditions. The ganglia were dissected free of any adherent tissue, treated with $2 \mathrm{ml}$ of $0.25 \%$ trypsin in HBSS for $45 \mathrm{~min}$ at $37^{\circ} \mathrm{C}$, and dissociated in L-15 $+10 \%$ FBS by trituration with a reduced-bore pipette. SCGs were dissected from embryonic day 21 rats under aseptic conditions. The ganglia were treated with $2 \mathrm{ml}$ of $0.25 \%$ trypsin and $0.2 \%$ collagenase in HBSS for $30 \mathrm{~min}$ and similarly dissociated. In each case, cells were pelleted by centrif ugation, resuspended, and maintained in a standard neuronal media consisting of MEM (Life Technologies) supplemented with 10\% FBS, 2 mM glutamine (Life Technologies), $0.4 \%$ glucose (Sigma), and $50 \mathrm{ng} / \mathrm{ml} 2.5 \mathrm{~S}$ NGF (Harlan Bioproducts for Science, Indianapolis, IN). Approximately 4000 neurons were plated onto $12 \mathrm{~mm}$ glass coverslips coated with ammoniated rat tail collagen (Biomedical Technologies, Stoughton, MA). Cultures were treated for 2.5 weeks with 5 -fluorodeoxyuridine and uridine (both at $10^{-5} \mathrm{M}$ ) (Sigma), which were added to the standard neuronal media on alternate feedings to eliminate non-neuronal cells.

Immunofluorescence staining and binding assays. Neurotrimintransfected and control cells were plated on eight-well glass slides (ICN Costa Mesa, CA). Cells were washed two times in L-15 supplemented with ITs + and incubated with anti-myc hybridoma ascites (1:600) in $\mathrm{L}-15-\mathrm{ITs}+$ media for $1 \mathrm{hr}$ at $4^{\circ} \mathrm{C}$. Cells were washed three more times with L-15-ITs + and incubated for $30 \mathrm{~min}$ with fluorescein-conjugated 
donkey anti-mouse IgG antiserum (Chemicon). Cells were fixed with $4 \%$ formalin for $15 \mathrm{~min}$ and mounted with Citifluor media (Ted Pella, Redding, CA) containing Hoechst dye.

For binding studies, cells were incubated with $2.5 \mu \mathrm{g} / \mathrm{ml}$ of purified $\mathrm{Ntm}-\mathrm{Fc}$ or COS cell conditioned media (containing $\sim 2 \mu \mathrm{g} / \mathrm{ml}$ of Ntm$\mathrm{Fc}$ ) for $1 \mathrm{hr}$ at $4^{\circ} \mathrm{C}$. After removal of the media, cells were incubated with an FITC-conjugated anti-human Fc antibody (1:100) (Jackson ImmunoResearch Laboratories, West Grove, PA) for $1 \mathrm{hr}$ at $4^{\circ} \mathrm{C}$. Alternatively, cells were incubated with a preformed complex of the Ntm-Fc and the anti-Fc antibody for $1 \mathrm{hr}$ at $4^{\circ} \mathrm{C}$. After they were washed, the cells were fixed with $4 \%$ formalin for $15 \mathrm{~min}$ and mounted. Similar procedures were followed for binding assays of Ntm-Fc to primary neurons. In some experiments, double labeling with the anti-neurofilament monoclonal antibody 3A10 was performed after binding of Ntm-Fc. Cultures were permeabilized with $0.2 \%$ Triton X-100 for $20 \mathrm{~min}$ at room temperature, rinsed in PBS, and blocked for $1 \mathrm{hr}$ in L-15 + 10\% FBS, followed by overnight incubation with 3A10 (1:10). The coverslips were washed once with PBS and then incubated sequentially with a biotinylated anti-mouse IgG (1:100) (Jackson ImmunoResearch) and streptavidin conjugated to Texas Red (1:500) (Amersham, Arlington Heights, IL). Digital photographs were taken with a CCD camera and analyzed with Metamorph software (Universal Imaging, West Chester, PA).

Flow cytometric analysis of $\mathrm{CHO}$ cells. Binding of Ntm-Fc to cells expressing the myc-tagged neurotrimin was assessed by flow cytometry. Transfected and control CHO cells in suspension were incubated for $1 \mathrm{hr}$ with the anti-myc ascites (1:600) in L-15-ITs + media at $4^{\circ} \mathrm{C}$. Cells were washed two times in L-15-ITs+ and incubated for 45 min with FITCconjugated donkey anti-mouse IgG antiserum (Chemicon). After they were washed three times, cells were either analyzed immediately by FACS or fixed with $2 \%$ formaldehyde for subsequent analysis. In separate experiments, CHO cells were prepared similarly and assayed for binding with $1 \mathrm{ml}$ of Ntm-Fc in L-15-ITs + media by analogous procedures. Analysis and sorting was performed with FACScan (Becton Dickinson, Mountain View, CA).

Neurite outgrowth assays. Dissociated E16 DRG, E21 SCG, and E18 hippocampal neurons were prepared as described previously (Rosen et al., 1992; Brewer, 1995) and plated in a serum-free neuron media (Felsenfeld et al., 1994). The ability of Ntm-Fc to promote the outgrowth of DRGs, SCGs, and hippocampal neurons was tested by immobilizing $100 \mu \mathrm{g} / \mathrm{ml} \mathrm{Ntm-Fc}$ on a nitrocellulose substrate prepared as described previously (Lagenaur and Lemmon, 1987). Neurite outgrowth on $\mathrm{Ntm}-\mathrm{Fc}$ was compared with that on 10 and $25 \mu \mathrm{g} / \mathrm{ml}$ laminin as positive controls, and $100 \mu \mathrm{g} / \mathrm{ml}$ MUC18-Fc and $1 \%$ BSA as negative controls. In some experiments, neurons were pretreated with and then plated and maintained in the presence of PI-PLC $(1 \mathrm{U} / \mathrm{ml})$ during the entire course of the experiment.

For neurite outgrowth assays on cells, monolayers of CHO-Ntm and control CHO cells were established by culturing 20,000 cells/well in eight-well slides. After allowing cells to attach overnight, $\sim 1000 \mathrm{DRG}$ or SCG neurons were added in serum-free media. In some studies, monolayers were pretreated with PI-PLC as described above. Neurons were allowed to grow for $8-14 \mathrm{hr}$ and were then washed, fixed with $4 \%$ formalin, permeabilized with methanol, and immunostained with a GAP-43 antibody as described (Williams et al., 1992).

To determine the effects of soluble Ntm-Fc on neurite outgrowth, dissociated DRGs were plated for $1 \mathrm{hr}$ on a collagen substrate prepared as described above. Thereafter, the media was replaced with media containing Ntm-Fc or MUC18-Fc (both at $10 \mu \mathrm{g} / \mathrm{ml}$ ). The same procedure was used for dissociated SCG neurons, which were plated on a laminin-coated substrate $(10 \mu \mathrm{g} / \mathrm{ml})$ as described above.

In each case, neurite length was measured from the tip of the longest neurite to the soma and was quantified by using the Universal Imaging System with the Metamorph software package. Measurements were performed only on single neurons. A total of 100 neurons pooled from at least three experiments were measured per condition.

ELISA assays. ELISA assays were performed to assess binding of soluble Ntm-Fc to collagen or laminin substrates. Plastic 96-well tissue culture plates (Nunc, Naperville, IL) were coated with collagen or with $10 \mu \mathrm{g} / \mathrm{ml}$ of laminin in carbonated buffer, $\mathrm{pH} \mathrm{9.5,} \mathrm{at} 4^{\circ} \mathrm{C}$ overnight. Purified Ntm-Fc diluted in carbonated buffer, $\mathrm{pH} 9.5$, or serum-free media at $4 \mu \mathrm{g} / \mathrm{ml}$ was added to each well and incubated at $4^{\circ} \mathrm{C}$ overnight. Wells were washed three times with PBS containing $0.05 \%$ Tween + $0.1 \%$ BSA. An anti-human Fc rabbit polyclonal antibody was diluted in the same buffer at 1:5000 $(0.5 \mu \mathrm{g} / \mathrm{ml})$ for $1 \mathrm{hr}$. After three washes with diluting buffer, an anti-rabbit antibody conjugated to alkaline phospha- tase (Jackson) $(1: 10,000)$ was added to the wells for $1 \mathrm{hr}$. The wells were rinsed three times with diluting buffer and one time with PBS alone. The alkaline phosphatase substrate $p$-nitrophenyl phosphate (Sigma) was added to each well for $30 \mathrm{~min}$ at a concentration of $1 \mathrm{mg} / \mathrm{ml}$, and the amount of the colorimetric reaction was quantitated at $405 \mathrm{~nm}$ in a Dynatech plate reader. All values were corrected by subtracting the readings of control wells that contained buffer or media alone.

\section{RESULTS \\ Generation and characterization of Ntm-expressing cells}

To facilitate studies of the function of neurotrimin in mediating cell-cell interactions, we expressed the protein at the surface of a heterologous cell line. Because various antisera raised against neurotrimin did not recognize this protein in its native conformation (Struyk et al., 1995), we generated a recombinant neurotrimin (Ntm-myc) in which a myc epitope tag was added between the third Ig domain and the GPI anchor. We expressed Ntm-myc in a CHO cell line that is poorly adherent (Pollard and Stanners, 1979) and has been shown to express other heterologous GPIanchored cell adhesion molecules at high levels (Benchimol et al., 1989; Gennarini et al., 1991). Isolation of the CHO cells that express Ntm (CHO-Ntm) was accomplished by pooling transfected cells, followed by selection of high-level expressing cells by FACS after staining with the anti-myc antibody. A stable control cell line was also generated by transfecting $\mathrm{CHO}$ cells with the pRC-CMV vector without any cDNA insert (CHO-CMV cells).

To characterize the expression of Ntm-myc in the CHO transfectants, we plated the sorted cells on slides and stained them with the anti-myc antibody. Most cells within the sorted population exhibited bright surface staining. When two cells expressing high levels of Ntm were in close apposition, Ntm typically accumulated at the sites of contact, suggestive of homophilic adhesion (Fig. $1 A$ ). In contrast, sites of contact between expressors and nonexpressors (CHO-CMV cells) plated together on the same dish did not demonstrate any accumulation of $\mathrm{Ntm}$, indicating that this concentration resulted from homophilic interactions (data not shown). Immunoprecipitation with the anti-myc monoclonal antibody from lysates of cells biotinylated with a membraneimpermeant reagent demonstrated a broadly migrating band of 65 $\mathrm{kDa}$ in CHO-Ntm (Fig. $1 B$ ), which ran with an expected $M_{\mathrm{r}}$ of 39 $\mathrm{kDa}$ after deglycosylation (data not shown); no proteins were detected from immunoprecipitates of control transfected cells. To confirm that Ntm-myc is anchored to the membrane by a GPI linkage, expressing and nonexpressing $\mathrm{CHO}$ cells were treated with PI-PLC. Cell lysates and supernatants from PI-PLC and mock-treated cultures were Western-blotted with the anti-myc monoclonal antibody (Fig. $1 C$ ). Of note, a prominent band was present in the supernatants of the PI-PLC-treated CHO-Ntm cells, whereas this protein band remained associated with the cells in the mock-treated cultures. Interestingly, the intensity of the $65 \mathrm{kDa}$ band increased after release with PI-PLC, presumably reflecting increased accessibility of the myc epitope. In other studies, we also found that the epitope tag was not accessible to the anti-myc antibody unless the protein was reduced.

\section{$\mathrm{Ntm}$ is present as homomeric complexes on the surface of $\mathrm{CHO}$ cells}

Neurotrimin contains seven cysteines over its three Ig-like domains, including a cysteine at position 83 that is not present in either OBCAM or LAMP (Struyk et al., 1995). This cysteine could potentially form an intermolecular disulfide bond, via either covalent dimerization of neurotrimin molecules or het- 
A.
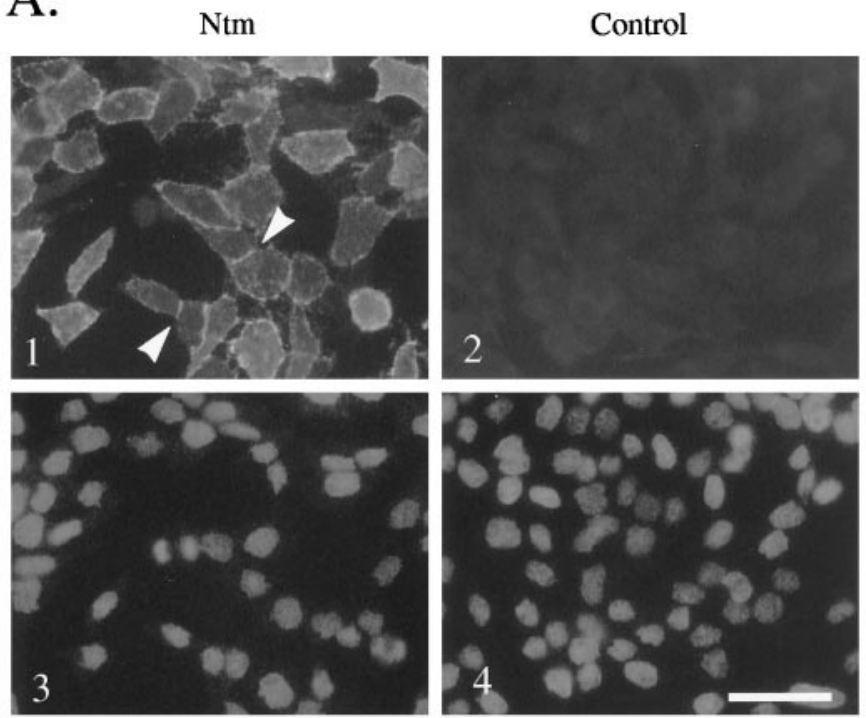

B.

$$
\text { 县总 } \mathrm{C} \text {. }
$$

216 kD-

105 kD-

$70.0 \mathrm{kD}-$

$42.0 \mathrm{kD}-$

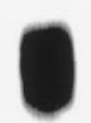

\section{0 kD-}

70.0 kD-

$42.0 \mathrm{kD}-$

$105 \mathrm{kD}-$

L $\quad$ S $\quad$ L $\quad$ S

PIPLC - - + +

216 kD-

.

28.0 kD-

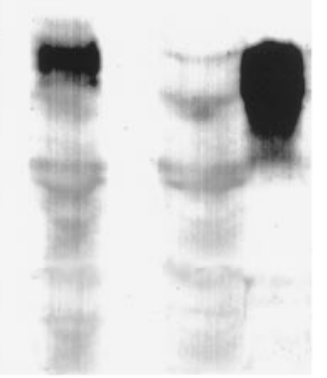

Figure 1. Characterization of Ntm-myc expression in transfected $\mathrm{CHO}$ cells. $A$, Immunofluorescence micrographs showing Ntm-myc expression on the surface of CHO-Ntm cells (panel 1) detected with an anti-myc antibody. Arrowheads indicate examples of the accumulation of $\mathrm{Ntm}$ at sites of cell-cell contact. Control cells transfected with the vector (panel 2) are not stained. The bottom panels show the Hoechst staining of the corresponding fields. Scale bar, $50 \mu \mathrm{m}$. B, Lysates of surface-biotinylated $\mathrm{CHO}-\mathrm{Ntm}$ and control cell monolayers were immunoprecipitated with the anti-myc antibody, electrophoresed, blotted, and probed with alkaline phosphatase-conjugated streptavidin. The prominent band migrating at 55-65 kDa, corresponding to the predicted size of Ntm, is present in immunoprecipitates of Ntm-myc cells but not control cells. Molecular weight markers are indicated at left. $C$, Western blot, with the anti-myc antibody, of supernatants $(S)$ and cell lysates $(L)$ of CHO-Ntm cultures either treated $(+)$ or mock-treated (-) with PI-PLC. A prominent band corresponding to Ntm-myc is present in the supernatant of PI-PLCtreated cultures but not in mock-treated cultures. Molecular weight markers are indicated at left.
A.

B.

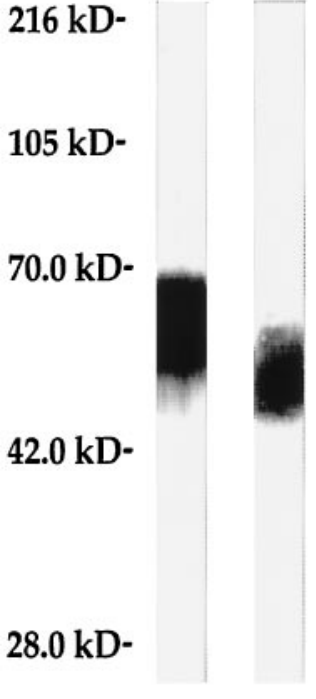

\section{Crosslinker}

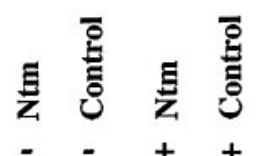

216 kD-

105 kD-

70.0 kD-

$42.0 \mathrm{kD}-$

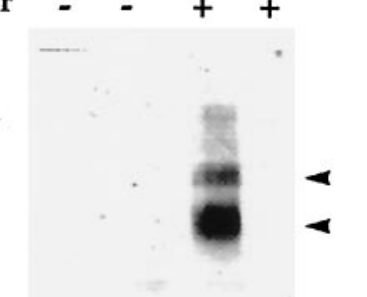

28.0 kD-

Figure 2. Ntm forms noncovalent homodimers. A, GPI-anchored proteins were extracted from confluent CHO-Ntm cells, electrophoresed under reducing (+DTT) or nonreducing $(-\mathrm{DTT})$ conditions, blotted, and detected with phosphatase alkaline-conjugated streptavidin. Note that $\mathrm{Ntm}$-myc is the only GPI-anchored protein expressed on the surface of CHO-Ntm cells and that there are no high molecular weight complexes under nonreducing conditions. Molecular weight markers are indicated at left. $B$, Proteins were immunoprecipitated from surface biotinylated CHO-Ntm or CHO-CMV cell lysates with the anti-myc antibody after treatment $(+)$ or mock-treatment $(-)$ with $\mathrm{BS}^{3}$. In the $\mathrm{BS}^{3}$-treated CHO-Ntm cells, all of the Ntm-myc migrates in two high molecular weight complexes (arrowheads) with mobilities of 130 and $180 \mathrm{kDa}$. Molecular weight markers are indicated at left.

erodimer formation with other cell-surface components. To examine whether $\mathrm{Ntm}$ is covalently linked to itself or other molecules, we biotinylated and prepared a purified GPI-anchored protein fraction as described previously (Rosen et al., 1992). Proteins were then fractionated by SDS-PAGE under both nonreducing and reducing conditions (Fig. $2 A$ ). Ntm-myc is the only GPI-anchored protein detected at the surface of the transfectants; no significant expression of other GPI-anchored proteins was detected on Ntm-myc or on control cells (data not shown). Of note, there was a slight increase in the mobility of the band representing Ntm-myc when proteins were run on SDS-PAGE under nonreducing compared with reducing conditions. This increased mobility under nonreducing conditions is frequently seen in monomeric IgCAMs because of the presence of intradomain disulfide bonds that stabilize a more compact conformation [for example, see Pedraza et al. (1990)]. These results indicate that neurotrimin does not form disulfide-linked multimers on the transfected cells.

To characterize further potential intermolecular interactions in which neurotrimin might participate, we used chemical crosslinking techniques. Monolayers of $\mathrm{CHO}-\mathrm{Ntm}$ cells were treated with the homobif unctional chemical cross-linker $\mathrm{BS}^{3}$ followed by biotinylation, immunoprecipitation with the anti-myc antibody, and SDS-PAGE. Most of the Ntm-myc was shifted to a molecular 
A.

B.

\section{Confluence Lo $\mathrm{Md} \mathrm{Hi}$}

216 kD-

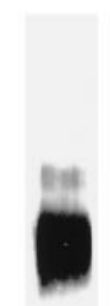

105 kD-

70.0 kD-

42.0 kD-

42.0 kD-

216 kD-

105 kD-
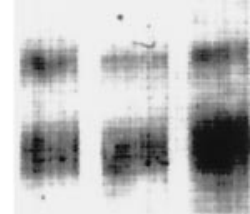

70.0 kD-

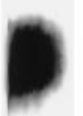

\section{0 kD-}

28.0 kD-
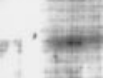

linking of Ntm-myc into larger complexes was equivalent at all cell densities, as demonstrated by comparable amounts of 130 and $180 \mathrm{kDa}$ protein bands present in each of the immunoprecipitates (Fig. $3 B$ ). This indicates that the decreased mobility of Ntm-myc after cross-linking results from intermolecular interactions on the surface of the same cell. Taken together, these results strongly suggest that neurotrimin is disposed in noncovalent complexes at the cell surface. Finally, to examine whether clustering is a general feature of GPI-anchored proteins, we performed similar cross-linking studies with $\mathrm{CHO}$ cells transfected with a recombinant form of the cell adhesion molecule $\mathrm{NgCAM}$, which was engineered to be GPI-anchored. Under identical conditions, this construct showed minimal dimer formation, indicating that dimerization of Ntm was specific (data not shown).

\section{Ntm mediates homophilic adhesion}

To determine whether Ntm mediates homophilic binding, we generated a recombinant, soluble form of Ntm consisting of its three Ig-like domains fused to a human $\mathrm{Fc}$ domain (Ntm-Fc). Characterization of the recombinant, soluble Ntm-Fc demonstrated that, as expected, it had a molecular weight of $85 \mathrm{kDa}$ under reducing conditions and $170 \mathrm{kDa}$ under nonreducing conditions, consistent with dimerization of the Fc domain. The deglycosylated, reduced protein ran at the predicted size of $\sim 60$ $\mathrm{kDa}$ (data not shown).

We next examined the ability of Ntm-Fc to bind to the Ntmexpressing and control CHO cells. For these studies, we used cells that were subjected to multiple rounds of FACS to isolate high expressor (HE) cells; the original population of transfected cells will be referred to as low expressor (LE) cells. We performed an immunofluorescence binding assay by incubating these cells sequentially with Ntm-Fc and a fluorescently labeled anti-human Fc antibody. (In other studies, we found that cross-linking with the anti-human Fc significantly stabilized the binding of the Ntm-Fc; data not shown.) In parallel, we visualized Ntm expression with the anti-myc antibody (Fig. 4). As noted above, in the HE population, Ntm-myc accumulates at sites of contact consistent with homophilic interactions (Fig. 4C). We observed significant $\mathrm{Ntm}-\mathrm{Fc}$ binding to $\mathrm{HE}$ cells, which correlated with the high level of Ntm expression by these cells. In double-label studies, Ntm-Fc appeared to be bound to those cells that expressed Ntm at the highest levels. When LE cells were used, staining with the antimyc antibody demonstrated fewer labeled cells, and binding of the Ntm-Fc exhibited lower intensity of binding, further suggesting that the binding of Ntm-Fc correlated with the levels of Ntm expression (data not shown).

To quantitate Ntm-Fc binding more precisely, we subjected the cells to a flow cytometric analysis of the levels of Ntm expression and, separately, the binding of the Ntm-Fc (Fig. 5). These studies demonstrated a strong correlation between the levels of Ntm-myc expression by transfected $\mathrm{CHO}$ cells and the amount of binding of Ntm-Fc to Ntm-myc cells observed in the previous immunofluorescence assay (Fig. 5). Ntm-Fc bound to the HE cells at much higher levels than to the LE cells; PI-PLC completely removed $\mathrm{Ntm}$ staining and $\mathrm{Ntm}-\mathrm{Fc}$ binding. In addition, a double-label FACS analysis with both anti-myc and the Ntm-Fc demonstrated a strong correlation between the level of Ntm-myc expression and the binding of Ntm-Fc to the transfected cells (data not shown). These results were complicated, however, by low-level crossreactivity of the secondary antibodies.

Finally, we examined whether Ntm promotes cell adhesion. In initial assays, we found that Ntm-myc cells consistently bound to

virtually all the cells were in contact, whereas very few cells were in direct contact at the lowest density. We found that cross- 
$\alpha-$ myc
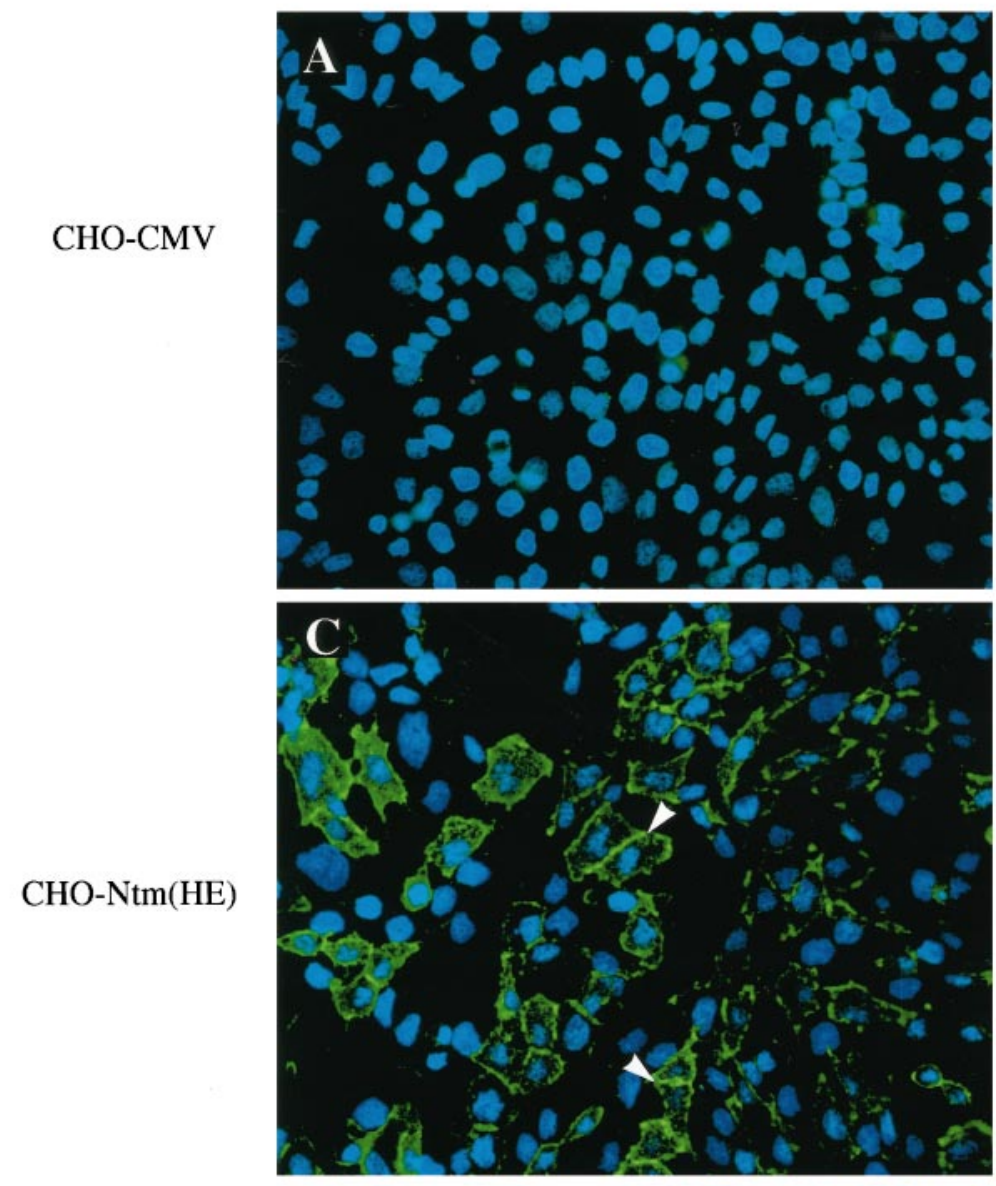

CHO-Ntm(HE)

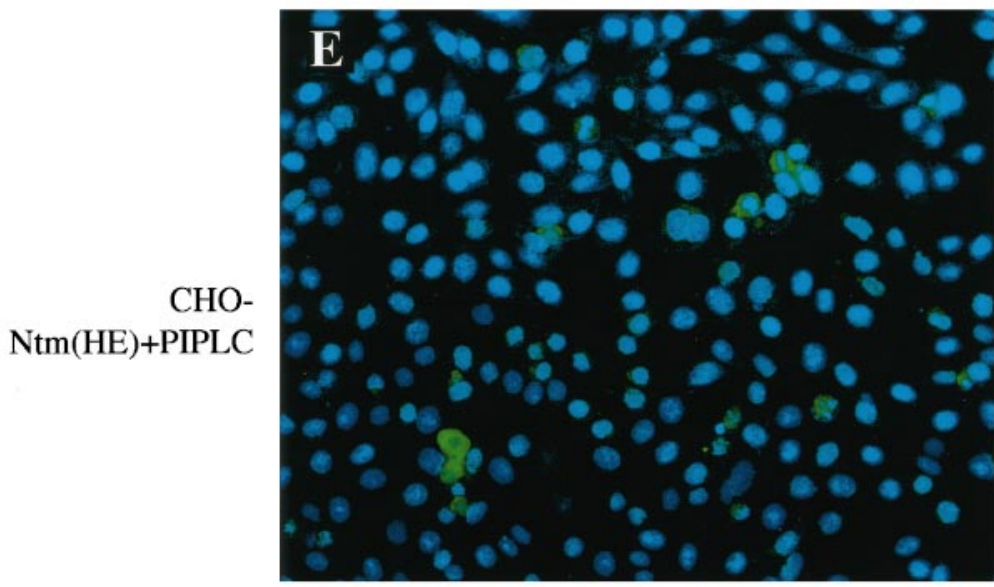

$\mathrm{Ntm}-\mathrm{Fc}$
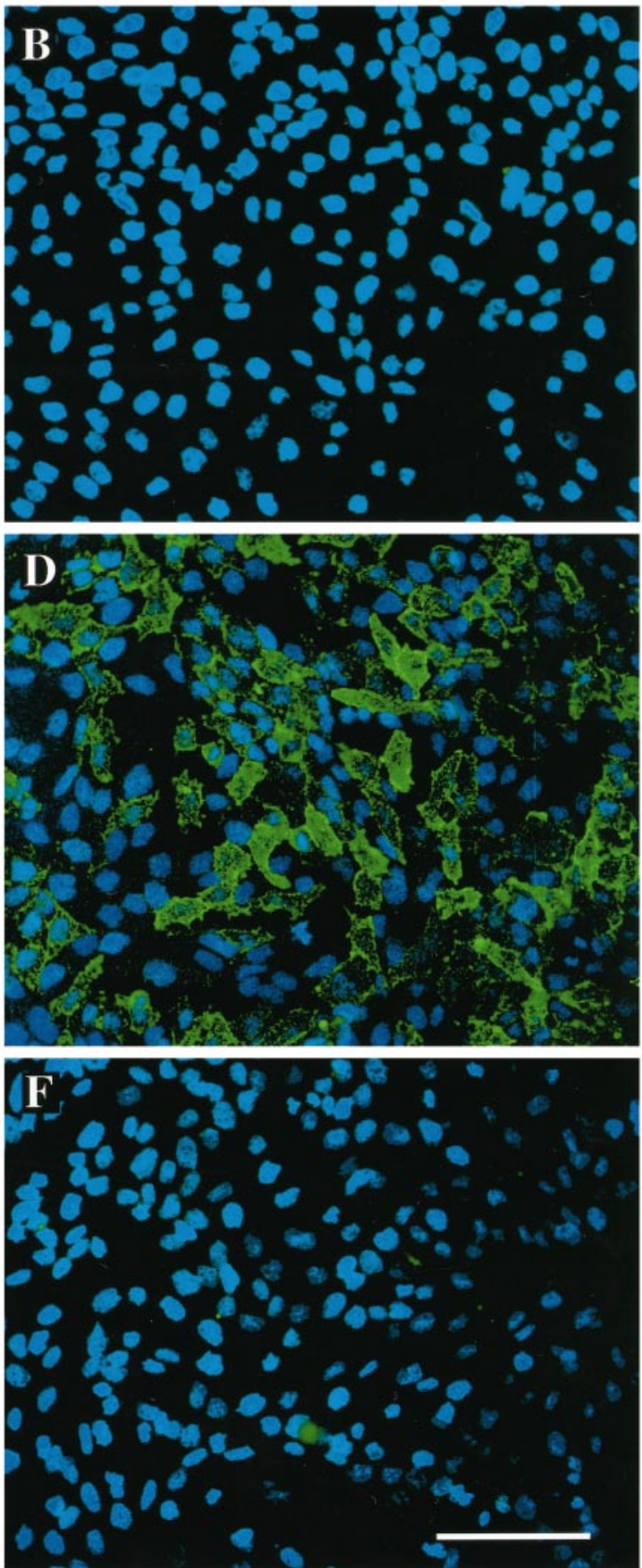

Figure 4. Ntm mediates homophilic binding. Fields corresponding to control $(A, B), \mathrm{CHO}-\mathrm{Ntm}(C, D)$, and CHO-Ntm cells pretreated with PI-PLC $(E$, $F$ ) were stained with the anti-myc antibody and FITC-conjugated anti-mouse $\operatorname{IgG}(A, C, E)$ or incubated with Ntm-Fc and FITC-conjugated anti-human Fc $(B, D, F)$. Examples of the accumulation of Ntm at sites of cell-cell contact are marked with arrowheads $(C)$. Scale bar, $100 \mu \mathrm{m}$.

Ntm-Fc adsorbed onto a plastic substrate, whereas few, if any, control cells attached. Pretreatment of the CHO-Ntm cells with PI-PLC abolished binding of these cells to Ntm-Fc but not the binding of these cells, or control cells, to fibronectin (data not shown). To demonstrate that Ntm promotes cell adhesion under more physiological conditions, we performed an aggregation assay with transfected and control CHO cells (Fig. 6). Dissociated Ntm-transfected and control CHO cells were incubated for $1 \mathrm{hr}$ at $37^{\circ} \mathrm{C}$. CHO-Ntm cells consistently formed large cell clusters in a time-dependent manner (Fig. 6A), whereas significantly fewer clusters were formed by control $(B)$ or $\mathrm{CHO}-\mathrm{Ntm}$ cells pretreated with PI-PLC $(C)$. Analysis of the aggregation kinetics (Fig. 6D) showed that there was a statistically significant difference between the Ntm versus the control $\mathrm{CHO}$ cells after $15 \mathrm{~min}$. To determine whether Ntm was promoting adhesion by a homophilic mechanism or was binding to another component at the $\mathrm{CHO}$ cell 


\section{CHO-CMV}
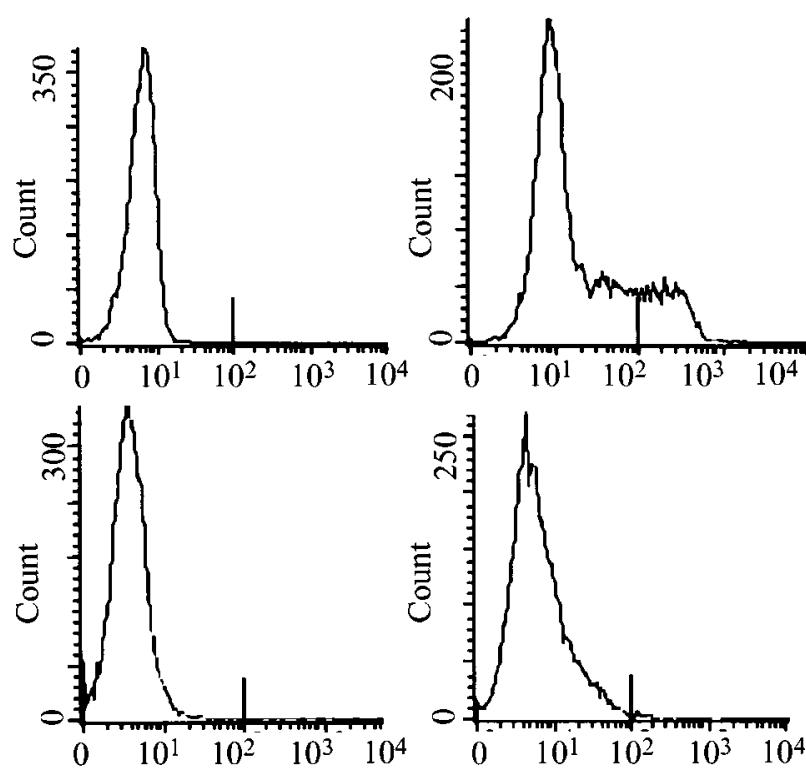

CHO-Ntm(LE)

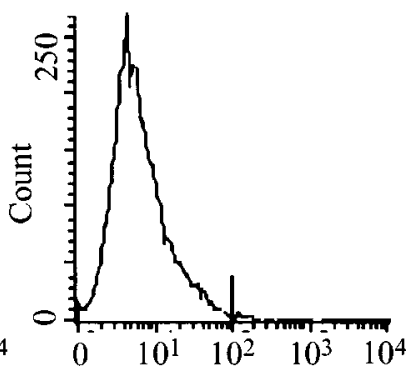

CHO-Ntm(HE)
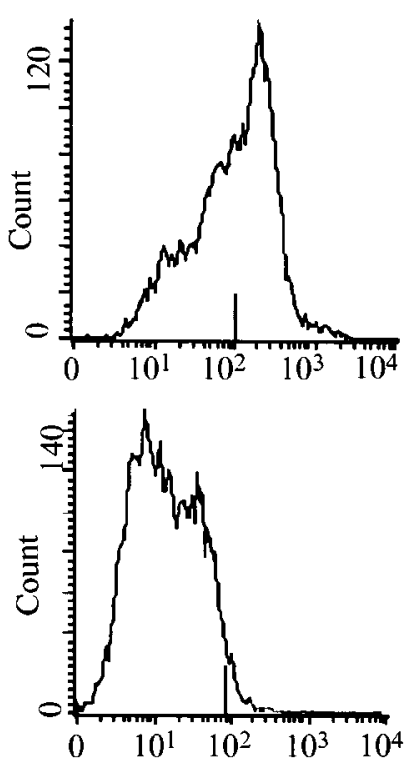

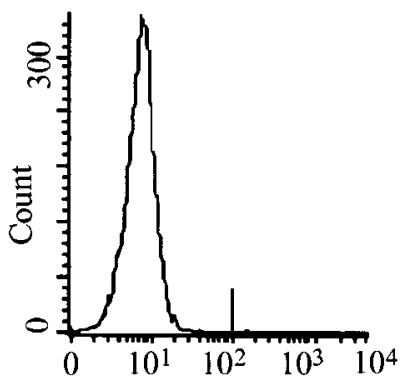

CHO-Ntm(HE) + PIPLC

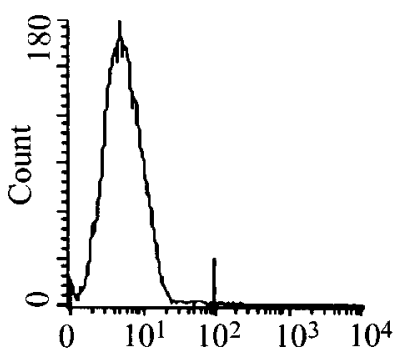

Figure 5. Quantitation of Ntm-Fc binding by flow cytometry. The top row show FACS analysis of the expression of Ntm-myc by control (CHO-CMV), CHO-Ntm $(L E), C H O-N t m(H E)$, and CHO-Ntm(HE) cells pretreated with PI-PLC [CHO-NTM(HE) + PIPLC]. Analysis of the binding of Ntm-Fc to the same sequence of cells is shown in the bottom row. The abscissa corresponds to the log of fluorescence intensity.

surface, we mixed, in a 1:1 ratio, dissociated CHO-Ntm cells prelabeled with the fluorescent dye diI and control cells labeled with the fluorescent dye diO. Examination of random aggregates under fluorescence microscopy indicated that most were composed of CHO-Ntm cells, consistent with a role of Ntm in promoting homophilic adhesion (Fig. $6 E$ ). As a further control, we mixed diI and diO prelabeled CHO-Ntm cells and found that the composition of the aggregates was evenly mixed $(F)$. Taken together, these results demonstrate that Ntm promotes homophilic adhesion.

\section{Ntm binds selectively to neurons that express Ntm}

We next tested whether Ntm binds to neurons via a homophilic mechanism or whether it might bind heterophilically as well. We chose DRG and SCG neurons for this assay because previous in situ hybridization and biochemical assays had shown that these neurons express IgLON family members at high and low levels, respectively (Rosen et al., 1992; Struyk et al., 1995). Based on PCR analysis, DRG neurons appear to express Ntm exclusively (data not shown). We examined the binding of Ntm-Fc to these neurons, visualizing neuronal fibers by staining for neurofilament. $\mathrm{Ntm}-\mathrm{Fc}$ bound to the great majority of DRG fibers, whereas binding to only a very small number of SCG fibers was observed (Fig. 7). Furthermore, the binding in both cases was restricted to neurons. The occasional Schwann cell or fibroblast that persists in these cultures was unlabeled, a finding confirmed in separate binding studies using purified Schwann cell cultures (data not shown). Pretreatment of the DRG neurons with PI-PLC eliminated all binding, consistent with a homophilic binding mechanism. In control studies, no binding of an Fc chimera of the lymphocyte adhesion molecule MUC18 was observed (data not shown). High-level binding of Ntm-Fc to hippocampal neurons was also observed, consistent with the high levels of Ntm expressed by these neurons (data not shown). These results strongly suggest that Ntm mediates stable homophilic, but not heterophilic, adhesion between Ntm-expressing neurons.

\section{Ntm promotes the outgrowth of DRG and hippocampal neurons and inhibits the outgrowth of SCG neurons}

To determine the effect of Ntm on neurite outgrowth, Ntm-Fc was immobilized on a nitrocellulose-coated substrate (Lagenaur and Lemmon, 1987). Immobilized laminin was used as a positive control; MUC18-Fc and BSA were used as negative controls. Hippocampal, DRG, and SCG neurons were plated onto proteincoated wells. Minimal binding or outgrowth of the neurons was observed with the MUC18-Fc or BSA substrates. In contrast, hippocampal and DRG neurons attached well to the Ntm-Fc and laminin substrates and extended neurites on both. The enhanced hippocampal outgrowth on Ntm was modest compared with that on laminin but was highly reproducible; the effects on DRG outgrow th were more robust (Fig. 8, and summarized in Table 1). A further, modest enhancement of hippocampal outgrowth was observed when neurons were grown on Ntm-Fc that was appropriately oriented by binding to an anti-human Fc antibody adsorbed to the nitrocellulose substrate (Table 1). In contrast, SCG neurons generally attached less well to Ntm-Fc and only extended neurites on laminin. PI-PLC treatment completely eliminated the outgrowth-promoting activity of Ntm on hippocampal neurons, but not its outgrowth-promoting activity on DRG neurons (Fig. 8). Under similar conditions, staining of DRG neurons for the GPI-anchored protein F3 was completely removed (data not shown). These results provide evidence that $\mathrm{Ntm}$ can promote the outgrowth of Ntm-expressing primary neurons (DRG and hippocampal neurons) but not of at least one neuron (i.e., SCG) that does not express Ntm. These results also suggest that Ntm may promote the outgrowth of hippocampal and DRG neurons by homophilic and heterophilic mechanisms, respectively, in view of the differential effect of PI-PLC on these two neurons. 

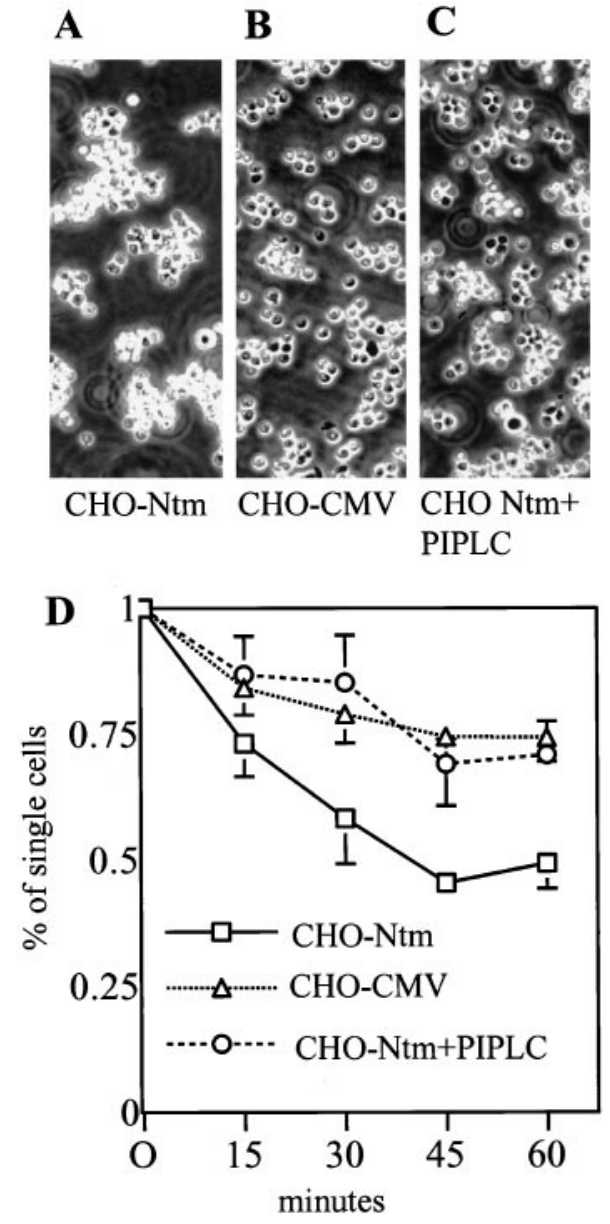

$\mathbf{E}$

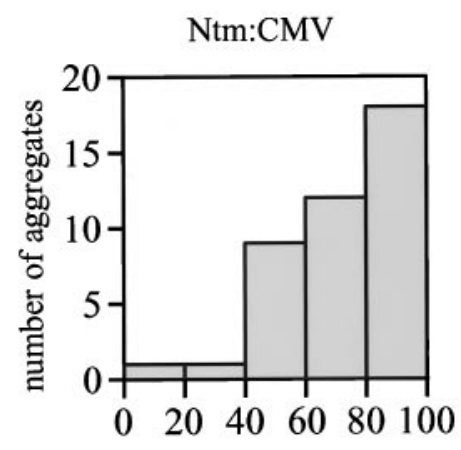

$\%$ CHO-Ntm cells

F

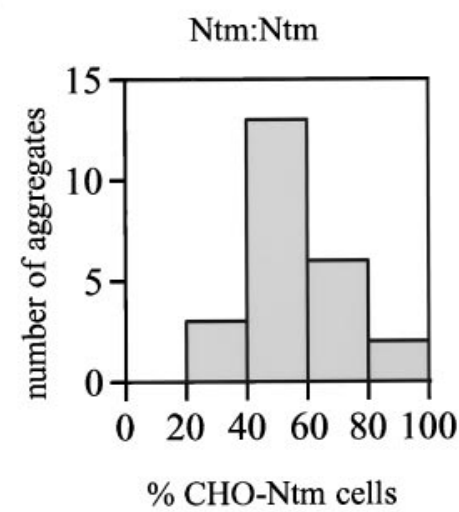

Figure 6. Transfected $\mathrm{CHO}$ cells reaggregate by a homophilic mechanism. $\mathrm{CHO}$ cells (Ntm, control, and Ntm pretreated with PI-PLC) were dissociated and allowed to reaggregate for $60 \mathrm{~min}$. Photomicrographs of representative aggregates that formed by Ntm-transfected $\mathrm{CHO}$ cells $(A)$, control CHO cells $(B)$, and Ntmtransfected $\mathrm{CHO}$ cells pretreated with PIPLC $(C)$ are shown. To examine the kinetics of reaggregation, aliquots were withdrawn at $15 \mathrm{~min}$ intervals, and single cells were counted in a hemocytometer $(D)$. Values are the mean \pm SEM for four independent experiments. Analysis of the composition of aggregates formed by a mixture of Ntm-transfected and control CHO cells demonstrates that aggregates are composed predominantly of Ntm-transfected cells $(E)$. Control mixture of CHO-Ntm labeled with diI and diO reveals that the composition of aggregates is equally mixed $(F)$.
To investigate further the possibility that Ntm has distinct effects on the outgrowth of DRG and SCG neurons and to examine its function in a more physiological environment, we assayed the outgrowth of these neurons on transfected $\mathrm{CHO}$ cell monolayers. Established monolayers of Ntm-expressing and control cells were seeded with $\sim 1000$ dissociated SCG or DRG neurons (Fig. 9). As an additional control, monolayers were pretreated, or mock-treated, with PI-PLC for $1 \mathrm{hr}$. (After PI-PLC treatment, Ntm-myc is not detectable at the cell surface at appreciable levels during the experimental time course.) Cultures were fixed after $14 \mathrm{hr}$, and the neurons and their processes were visualized by staining for GAP-43.

Significant neurite outgrowth of both SCG and DRG neurons was observed on the control cells, possibly reflecting the activity of neuronal integrins on the matrix deposited by the cells (Reichardt et al., 1990). Of note, the neurite outgrowth of DRG neurons was significantly longer on the Ntm-transfected cells compared with the control cells. Thus, the mean neurite length was $165 \mu \mathrm{m}$ on the Ntm-transfected cells compared with $105 \mu \mathrm{m}$ on the control cells. Strikingly, the presence of Ntm on the surface of CHO cells had the opposite effect on SCG neurons: the mean neurite length of the SCG neurons was $216 \mu \mathrm{m}$ on the control cells, whereas it was $150 \mu \mathrm{m}$ on the transfected cells. Pretreatment of the monolayers with PI-PLC resulted in a neurite outgrowth similar to that on control cells for both DRG and SCG neurons. The results of these experiments demonstrated that the presence of Ntm on the surface of CHO cells had significant but opposing effects on the outgrowth of DRG and SCG neurons.

\section{Soluble Ntm regulates the outgrowth of DRG and SCG neurons}

We next determined whether Ntm regulates the outgrowth of DRG and SCG neurons by modulating the adhesive character of the substrate or, alternatively, whether it can mediate its effects directly as a soluble molecule. To this end, neurons were allowed to attach to permissive substrates, and the outgrowth was determined in the presence or absence of soluble Ntm-Fc. DRG neurons were grown on collagen, which has a relatively weak outgrowth-promoting activity (O. Gil and J. Salzer, unpublished observations), whereas SCG neurons were grown on laminin, which strongly promotes their outgrowth and would therefore more easily reveal an inhibitory effect of Ntm. We found that the addition of Ntm-Fc to DRG neurons significantly stimulated their outgrowth compared with MUC18-Fc (Fig. 10A). By contrast, Ntm-Fc had an inhibitory effect on the outgrowth of SCG neurons (Fig. 10B). Thus, the mean neurite length of DRG neurons was $109 \mu \mathrm{m}$ in the presence of Ntm-Fc $(10 \mu \mathrm{g} / \mathrm{ml})$ and $73 \mu \mathrm{m}$ in the presence of MUC18-Fc $(10 \mu \mathrm{g} / \mathrm{ml})$. In contrast, the mean neurite length of SCG neurons was $123 \mu \mathrm{m}$ in the presence of Ntm-Fc and $192 \mu \mathrm{m}$ in the presence of MUC18-Fc. These results confirm the reciprocal effects of $\mathrm{Ntm}$ on the outgrowth of these two populations of neurons and strongly suggest that Ntm mediates its effects as a soluble protein and does not need to be substrateassociated. The results from all of the outgrowth studies are summarized in Table 1.

To examine whether these effects of Ntm-Fc on neurite out- 

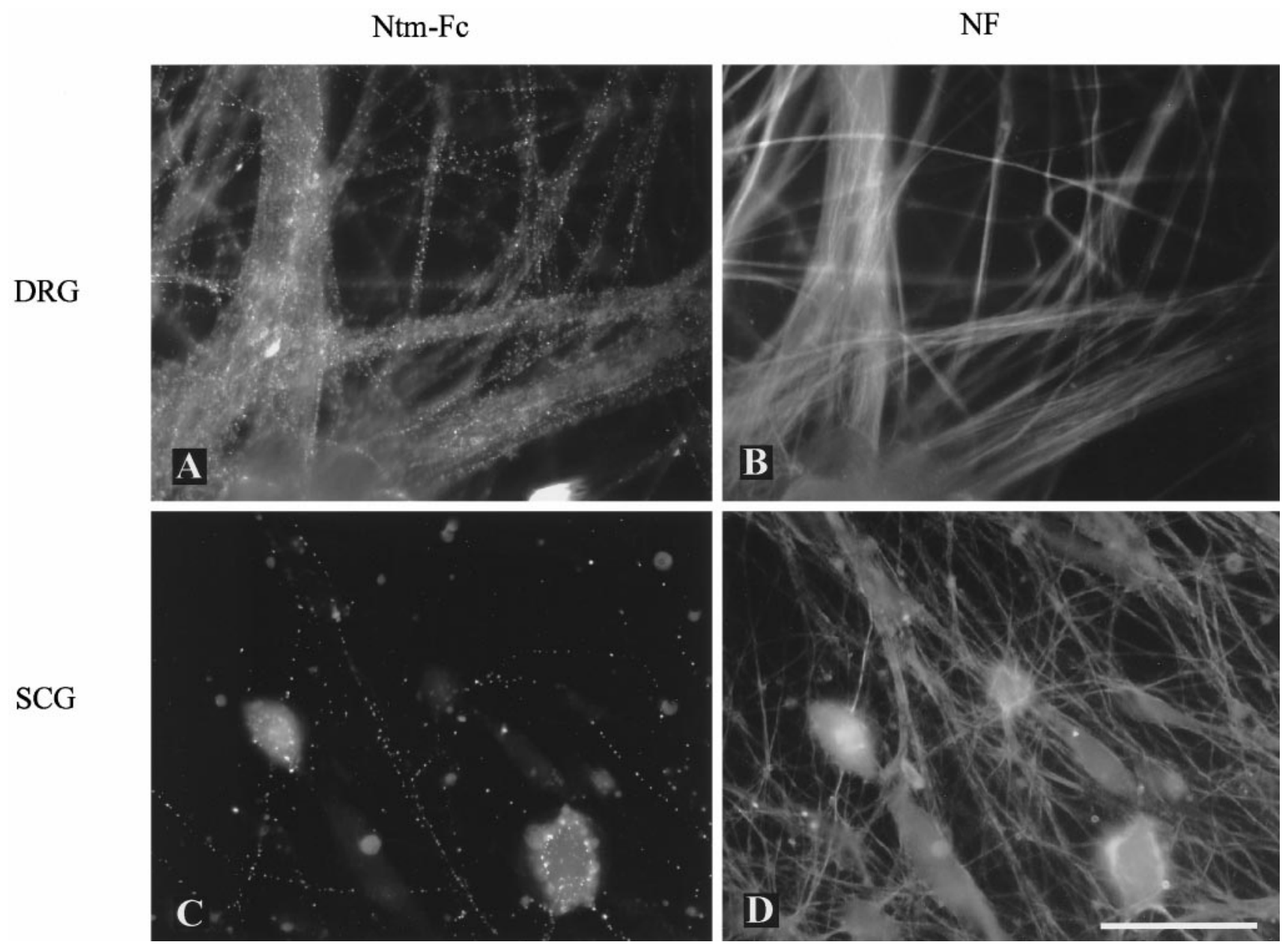

Figure 7. Binding of Ntm-Fc to primary neurons. Cultures of dissociated DRG $(A, B)$ and SCG neurons $(C, D)$ are shown. Ntm-Fc binding $(A, C)$ and neurofilament staining $(B, D)$ are shown. Note that Ntm-Fc binds to the great majority of the DRG neurites but to only a few of the SCG neurites. Scale bar, $50 \mu \mathrm{m}$.

growth truly reflected its activity as a soluble molecule and did not result from its adherence to the collagen or laminin substrates, we performed a series of ELISAs (Fig. 10C). As a positive control, we demonstrated substantial binding of $4 \mu \mathrm{g} / \mathrm{ml} \mathrm{Ntm-Fc}$ to the unmodified plastic substrate. Ntm-Fc diluted in serum-free media containing $1 \%$ BSA also exhibited significant binding to the plastic substrate, although it was reduced about threefold compared with Ntm-Fc diluted in PBS. By contrast, there was negligible binding of Ntm-Fc to either the collagen or laminin substrates (Fig. 10C). These results strongly suggest that Ntm-Fc did not bind to the collagen or laminin substrates during the course of the neurite outgrowth assays but rather regulated outgrowth as a soluble protein.

\section{DISCUSSION}

We have demonstrated that $\mathrm{Ntm}$ forms homomeric complexes within the plane of the membrane and mediates homophilic adhesion. We have also shown that Ntm binds specifically to DRG and hippocampal neurons, which express Ntm, and not to SCG neurons, which do not. Finally, we have demonstrated that $\mathrm{Ntm}$ promotes the outgrowth of DRG neurons and inhibits the outgrowth of SCG neurons. These results further support the specificity of the IgLON family in promoting system-specific projections and provide new insights into the mechanisms of their activity.

\section{$\mathrm{Ntm}$ forms homomeric complexes: potential role in promoting adhesion}

Several lines of evidence indicate that Ntm mediates homophilic binding and adhesion. Transfected $\mathrm{CHO}$ cells that express Ntm bind to both soluble and substrate-bound Ntm-Fc. In addition, $\mathrm{Ntm}$ accumulates at sites of cell contact between expressors (Figs. $1,4)$ but not between expressors and control cells. Finally, transfected $\mathrm{CHO}$ cells placed in suspension reaggregate more than control cells (Fig. 6). These results, together with previous studies demonstrating that LAMP mediates homophilic interactions ( $\mathrm{Pi}-$ menta et al., 1995; Zhukareva and Levitt, 1995), indicate that members of the IgLON family promote homophilic adhesion.

We have found that Ntm is present on the surface of transfected cells as a noncovalent dimer and, to a lesser extent, as homomultimers (Figs. 2,3). Our results suggest this is not a feature of all GPI-anchored cell adhesion molecules or an artifact of increased planar mobility of the GPI anchor, because minimal cross-linking of a GPI-anchored form of $\mathrm{NgCAM}$ was observed under comparable conditions. However, several other GPIanchored proteins were recently shown to cross-link into similar, higher order complexes in transfected cells (Friedrichson and 

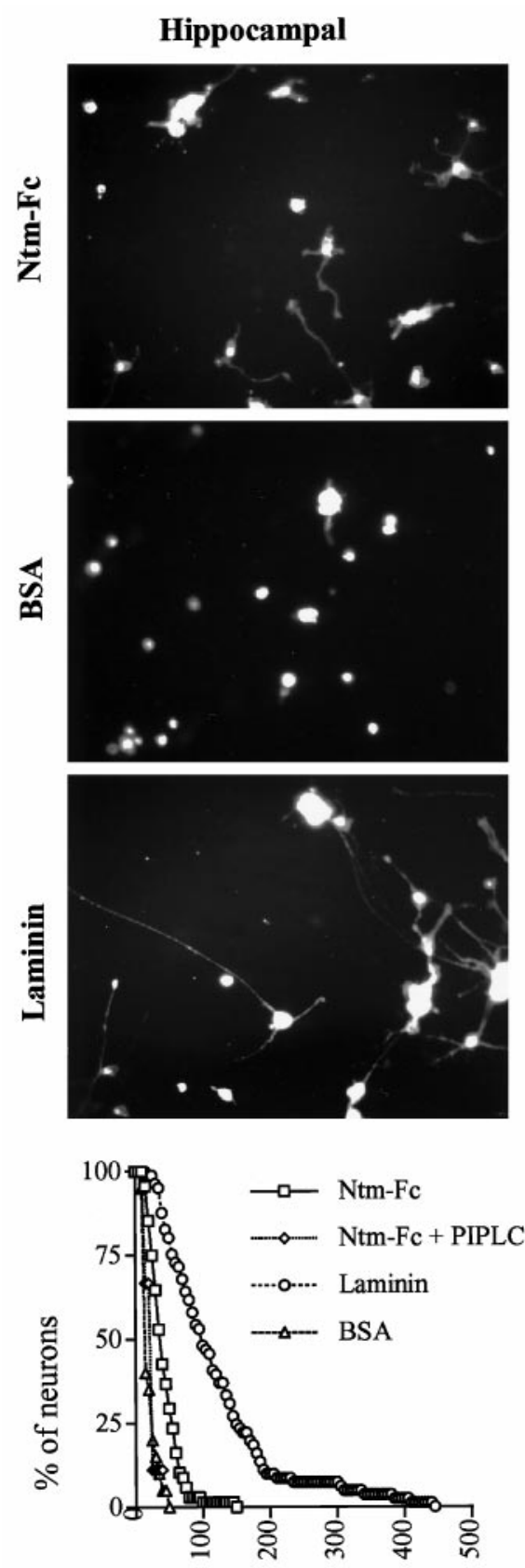

neurite length
DRG
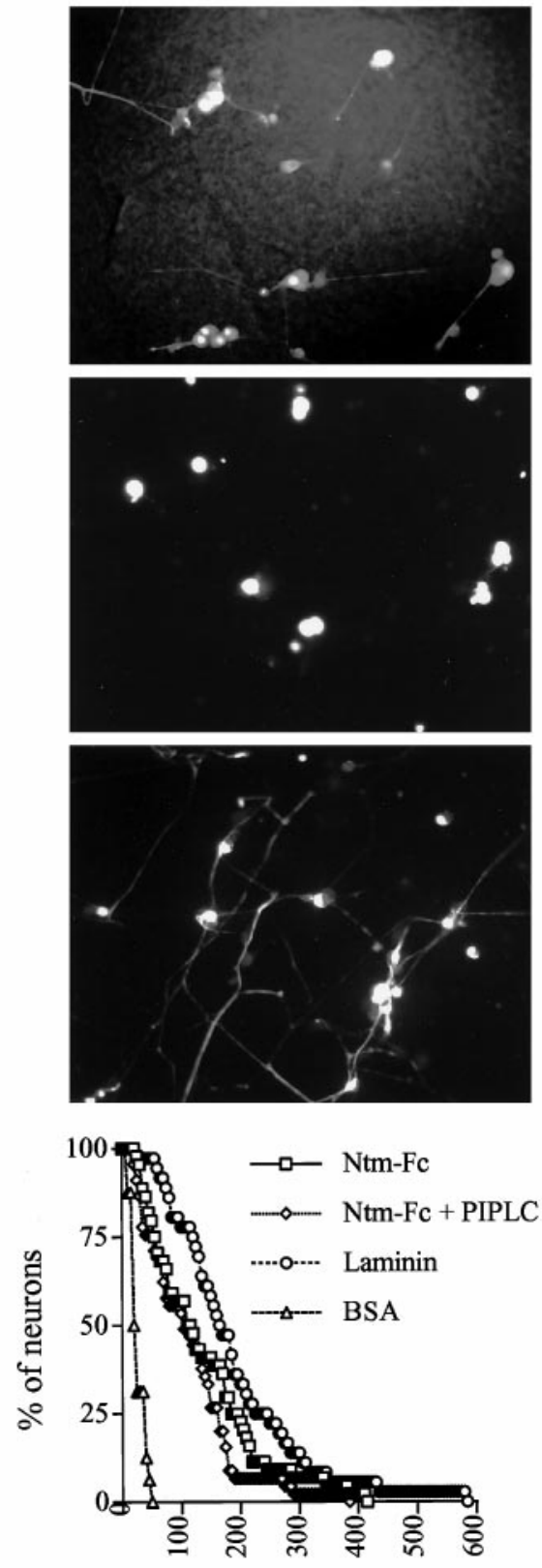

neurite length
SCG
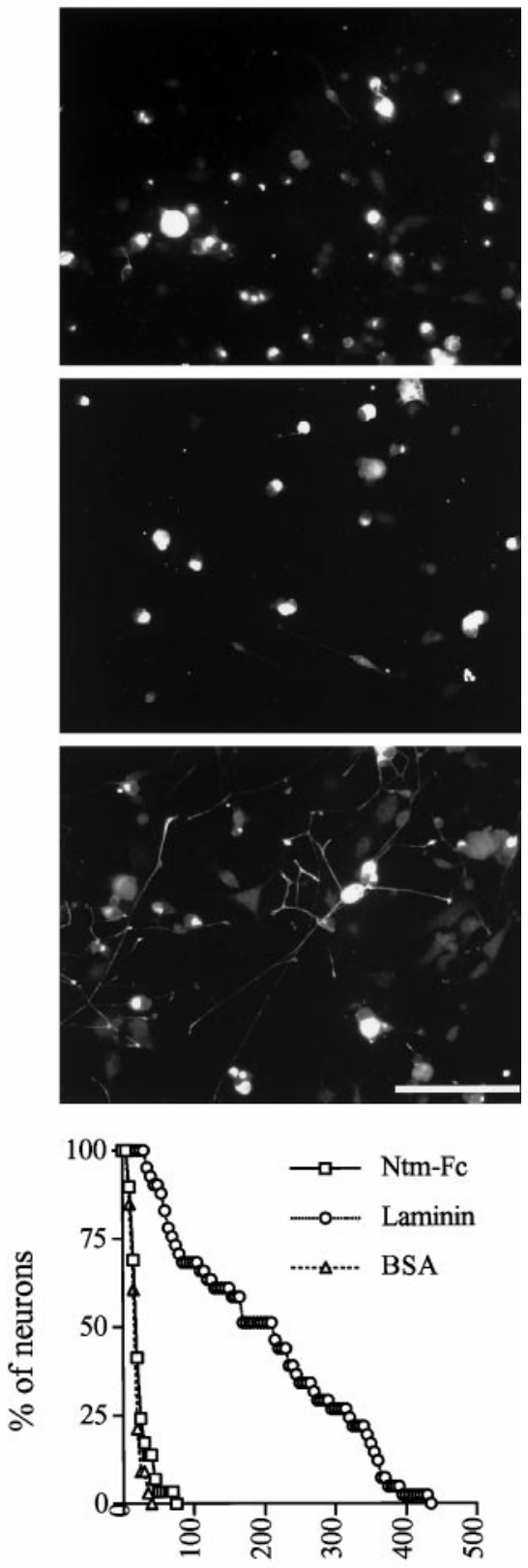

neurite length

Figure 8. Ntm-Fc promotes hippocampal and DRG but not SCG neurite outgrowth. Photomicrographs show neurons cultured on $100 \mu \mathrm{g} / \mathrm{ml}$ Ntm-Fc, $1 \%$ BSA, or $10-25 \mu \mathrm{g} / \mathrm{ml}$ laminin adsorbed to nitrocellulose substrates. Hippocampal neurons (left column) were prelabeled with diI, whereas sensory (center column) and sympathetic neurons (right column) were stained with the neurofilament-specific antibody 3A10. Quantitation of the outgrowth for each cell type is shown in the graphs at the bottom. Scale bar, $100 \mu \mathrm{m}$.

Kurzchalia, 1998). Taken together, these findings suggest enrichment of these proteins into membrane microdomains (Friedrichson and Kurzchalia, 1998; Varma and Mayor, 1998) or a tendency of such proteins to multimerize. Because all of these studies were performed on transfected cells, it will be important in the future to determine whether Ntm also exists as a noncovalent multimer at the surface of neurons and, if so, whether other IgLON family members also form higher order complexes alone or with $\mathrm{Ntm}$. Ntm may also potentially interact noncovalently or covalently, via its extra cysteine, with transmembrane proteins that are specifically co-expressed on neurons and are not present on CHO cells.

As with other CAMs and signaling receptors, the ability of Ntm to form homodimers and oligomers may be critical for its function. P0, the major protein of peripheral nerve myelin, forms tetramers that bind to $\mathrm{P} 0$ tetramers of the apposed membrane, thereby promoting adhesion between the closely spaced myelin lamellae (Shapiro et al., 1996). Dimerization is required for the adhesive function of the cadherins (Brieher et al., 1996; Tomschy 


\begin{tabular}{lccc}
\hline \multicolumn{2}{l}{ Table 1. Summary of neurite outgrowth assays } & & \\
& DRG & Hippocampal & SCG \\
\hline Ntm-Fc (bound) & & \\
Ntm-Fc $(100 \mu \mathrm{g} / \mathrm{ml})$ & $136.42 \pm 23.27^{*}$ & $41.92 \pm 3.94^{*}$ & $21.03 \pm 3.07$ \\
Anti-Fc + Ntm-Fc & nd & $56.76 \pm 6.53^{*}$ & nd \\
Ntm-Fc + PI-PLC & $144.56 \pm 23.4^{*}$ & $20.57 \pm 0.38$ & nd \\
Laminin $(10,25,10 \mu \mathrm{g} / \mathrm{ml})$ & $149.47 \pm 0.89^{*}$ & $103.73 \pm 5.82^{*}$ & $198.79 \pm 34.49^{*}$ \\
MUC18-Fc $(100 \mu \mathrm{g} / \mathrm{ml})$ & $23.66 \pm 1.63$ & $19.87 \pm 0.54$ & $16.16 \pm 2.37$ \\
Ntm-Fc (soluble) & & & \\
Ntm-Fc $(10 \mu \mathrm{g} / \mathrm{ml})$ & $109.33 \pm 5.64^{*}$ & nd & $122.89 \pm 29.24$ \\
MUC18-Fc $(10 \mu \mathrm{g} / \mathrm{ml})$ & $72.18 \pm 4.8$ & nd & $191.88 \pm 49.18$ \\
Transfected cells & & nd & $149.90 \pm 19.21^{*}$ \\
CHO-Ntm & $165.02 \pm 14.38^{*}$ & nd & $218.02 \pm 11.29$ \\
CHO-Ntm + PI-PLC & $129.52 \pm 9.91$ & nd & $215.70 \pm 12.26$ \\
CHO-CMV & $104.94 \pm 4.25$ & &
\end{tabular}

This table summarizes the outgrowth of different primary neurons grown on Ntm-Fc bound to nitrocellulose, on extracellular matrix substrates with soluble Ntm-Fc added to the media, and on transfected CHO cells. Neurite outgrowth was quantified by image analysis, as described in Materials and Methods, and expressed as a mean neurite length \pm SEM. At least three independent experiments were performed for each condition, except for the Anti-Fc $+\mathrm{Ntm}-\mathrm{Fc}$ for which two experiments were performed. *Indicates a significant difference $(p<0.05)$ from control according to Student's $t$ test. nd, Not determined.

et al., 1996), which form a linear adhesion "zipper" (Shapiro et al., 1995; Nagar et al., 1996). Growth factor receptors dimerize after ligand binding, resulting in receptor autophosphorylation and activation of intracellular signaling pathways (Schlessinger and Ullrich, 1992). Inhibition of neurite outgrowth mediated by the semaphorins also appears to depend on dimerization (Klostermann et al., 1998; Koppel and Raper, 1998). Whether the ability of Ntm to promote adhesion and regulate neurite outgrowth requires dimerization or higher-order complexes is not yet known.

\section{Ntm has bifunctional effects on outgrowth that are mediated by homophilic and heterophilic mechanisms}

A major finding of this paper is that Ntm has dual effects on neurite outgrowth, promoting the outgrowth of DRG and inhibiting the outgrowth of SCG neurons. The ability of CAMs to have dual effects on neurite outgrowth is becoming well recognized. Myelin-associated glycoprotein promotes the outgrowth of newborn DRG neurons and inhibits that of mature DRG neurons and postnatal cerebellar neurons (Mukhopadhyay et al., 1994). Similarly, F3 has cell type-specific effects, promoting the outgrowth of DRG neurons (Durbec et al., 1992) and inhibiting the outgrowth of cerebellar granule cells (Buttiglione et al., 1996); its precise effect on outgrowth appears to be modulated by interactions with TAG-1 (Buttiglione et al., 1998). Netrin-1 attracts commissural neurons (Serafini et al., 1994) but repels trochlear neurons (Colamarino and Tessier-Lavigne, 1995). The findings reported here indicate that in addition to the netrins, semaphorins, and ephrins, many IgCAMs, including the IgLON family, have cell typespecific inhibitory effects on neurite outgrowth.

The ability of Ntm-Fc to inhibit the outgrowth of SCG neurons despite binding to only a small number of nerve fibers indicates that inhibition does not require formation of a stable adhesive complex of the type measured by the immunofluorescence binding assay. The inhibitory effects on SCG outgrowth are of particular interest because these neurons express very low levels of the IgLON family (Rosen et al., 1992), likely on the few nerve fibers to which Ntm-Fc does bind. These results indicate that Ntm must interact heterophilically with an SCG receptor to inhibit the outgrowth of these neurons. Similarly, PI-PLC treatment of DRG neurons [which removes Ntm from the surface of these neurons (C. Rosen and J. Salzer, unpublished observations)] abolishes the binding of Ntm-Fc but not its ability to promote neurite outgrowth (Fig. 8). These results further support the existence of a heterophilic receptor or receptors that regulate outgrowth. These findings resemble those of a previous report (Felsenfeld et al., 1994) that demonstrated that TAG-1 binding is homophilic, whereas its effects on outgrowth are heterophilic, mediated via the activity of L1 and $\beta 1$ integrins. The nature of the heterophilic receptor on DRG neurons and whether it mediates the inhibitory activity of Ntm-Fc on SCG neurons are important questions for future study.

The inhibitory activity of Ntm reported here is also consistent with the striking inhibitory effect on neurite outgrowth of gp55, which corresponds to a mixture of chick LAMP and OBCAM (Wilson et al., 1996; Clarke and Moss, 1997). These authors also report that gp55 inhibits binding of neurons to different substrates (Clarke and Moss, 1997). We have found that Ntm strongly promotes DRG but not SCG neuron attachment (O. Gil, G. Zanazzi, and J. Salzer, unpublished observations); our studies to date have been inconclusive as to whether Ntm is anti-adhesive for SCG neurons. Interestingly, the effects of gp55 on outgrowth were observed with chick E9 DRG neurons, which have not yet begun to express these proteins, indicating a heterophilic mechanism of inhibition (Clarke and Moss, 1997). It is not yet known whether these chick IgLON members will promote the outgrowth of older DRG neurons that express gp55.

\section{Potential role of the IgLON family in the development of neural projections}

Ntm and LAMP are largely expressed in complementary locations within the nervous system. Thus, LAMP is principally confined to limbic cortex (Levitt, 1984), whereas Ntm is expressed mostly in sensorimotor cortex (Struyk et al., 1995). In addition, $\mathrm{Ntm}$ and LAMP are differentially expressed in the developing basal ganglia and thalamus with topologically graded distributions. For example, Ntm is expressed predominantly in the rostral dorsolateral striatum, which projects to the sensorimotor neocortex, and LAMP is expressed in the medial portion, which projects to the limbic cortex. The differential distribution of these pro- 

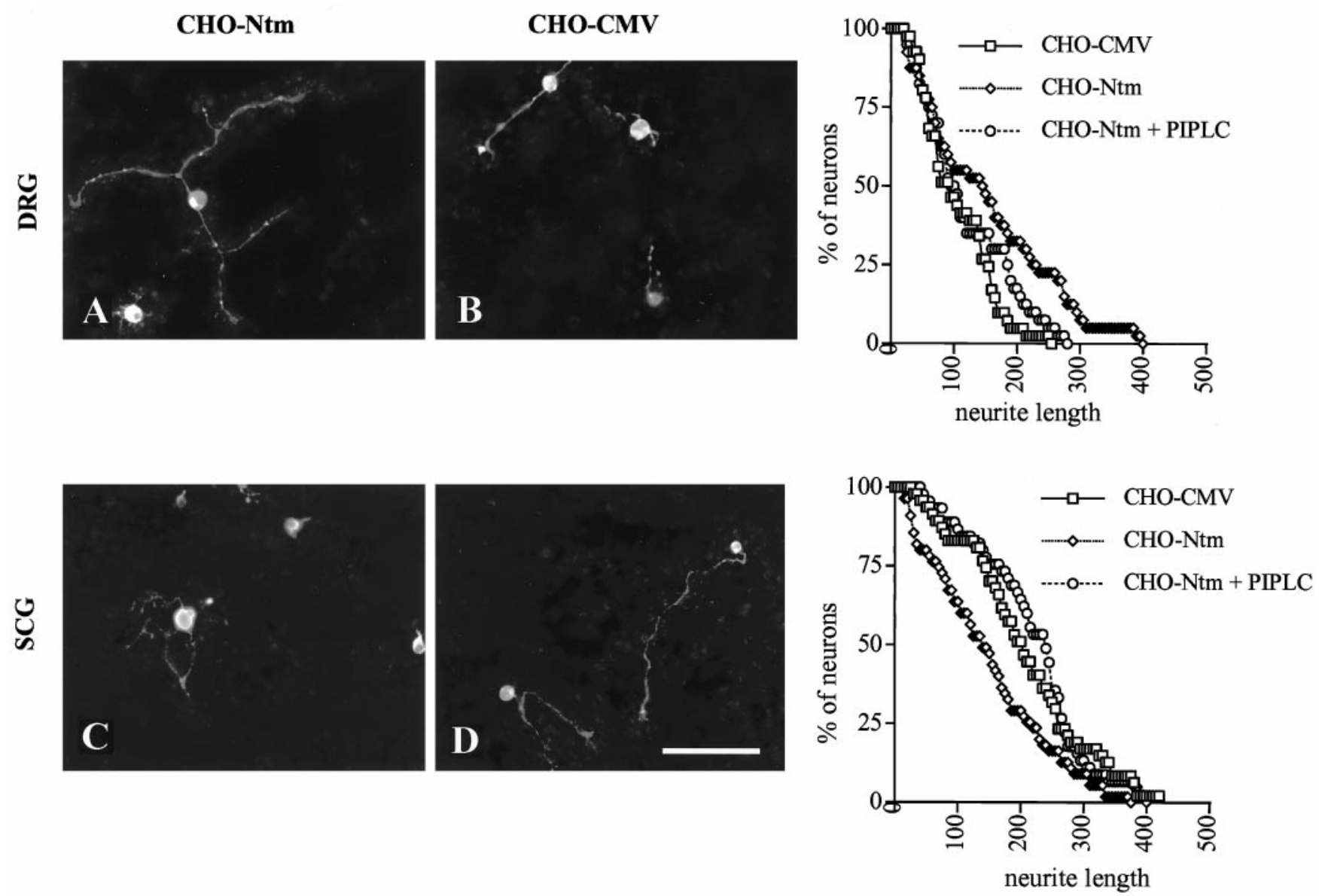

Figure 9. Ntm promotes DRG and inhibits SCG neurite outgrowth. Photomicrographs show DRG $(A, B)$ and SCG $(C, D)$ neurons cultured on a monolayer of Ntm-transfected $\mathrm{CHO}$ cells $(A, C)$ or $\mathrm{CHO}$ cells transfected with the vector $(B, D)$. Cultures were fixed and stained for neurofilament after an additional $14 \mathrm{hr}$. Graphs showing quantitation of neurite outgrowth for each cell type are on the right. Scale bar, $100 \mu \mathrm{m}$.

teins, together with emerging evidence that they have distinct, bifunctional effects on neurite outgrowth, strongly suggest that Ntm and LAMP regulate the development of neuronal projections via outgrowth-promoting and -inhibiting activities. Interestingly, recent studies suggest that LAMP inhibits the outgrowth of neurons from the lateral thalamus that project to the neocortex (Mann et al., 1997); this region of the thalamus is known to express low levels of LAMP and high levels of Ntm [Struyk et al. (1995) and O. Gil and J. Salzer, unpublished observations], suggesting that heterophilic interactions within the IgLON family could have inhibitory effects.

\section{Ntm regulates neurite outgrowth as a soluble molecule}

Like other IgCAMs such as F3 and L1, which can regulate neurite outgrowth as soluble molecules (Durbec et al., 1992; Doherty et al., 1995), we have shown that soluble Ntm is active, promoting DRG and inhibiting SCG neurite outgrowth. Many GPIanchored proteins exist as both membrane-associated and soluble molecules, although the mechanism(s) regulating release of these proteins from the cell surface is not yet clear (for review, see Salzer et al., 1996; Faivre-Sarrailh and Rougon, 1997). These findings suggest that a potential function of the GPI anchor may be to permit the regulated release of these proteins, thereby allowing soluble CAMs to promote or inhibit outgrowth in a regional manner.

The ability of soluble CAMs to regulate outgrowth suggests that they function by activating intracellular signaling pathways; such pathways remain poorly understood. In the case of the IgLON family, direct evidence of such an activation and clues to the pathways involved have been provided by recent studies demonstrating that a soluble form of LAMP elicits an increase in intracellular calcium via L-type channels (Zhukareva et al., 1997), whereas the inhibitory effects of gp55 are sensitive to ribosylation of G-proteins by pertussis toxin (Clarke and Moss, 1997). These findings raise the question of how these GPIanchored CAMs activate signaling pathways. One possibility is that they bind to a transmembrane signaling receptor, possibly consistent with the heterophilic inhibition of Ntm on SCG neurons and of gp55 on E9 DRG neurons (Wilson et al., 1996). Alternatively, the PI-PLC sensitivity of hippocampal neurons, like LAMP-promoted outgrowth (Zhukareva and Levitt, 1995), suggests that some effects on neurite outgrowth may result from homophilic interactions. In the latter case, Ntm, like other GPIanchored proteins, may associate with nonreceptor tyrosine kinases in glycosphingolipid-enriched membrane domains (FaivreSarrailh and Rougon, 1997; Henke et al., 1997) or promote outgrowth via cis interactions with neuronal transmembrane proteins (Peles et al., 1997; Galbiati et al., 1998).

In sum, these studies suggest that the distinct expression of IgLON members promotes the development of system-specific projections by a combination of growth-promoting and -inhibiting 
$\mathbf{A}$

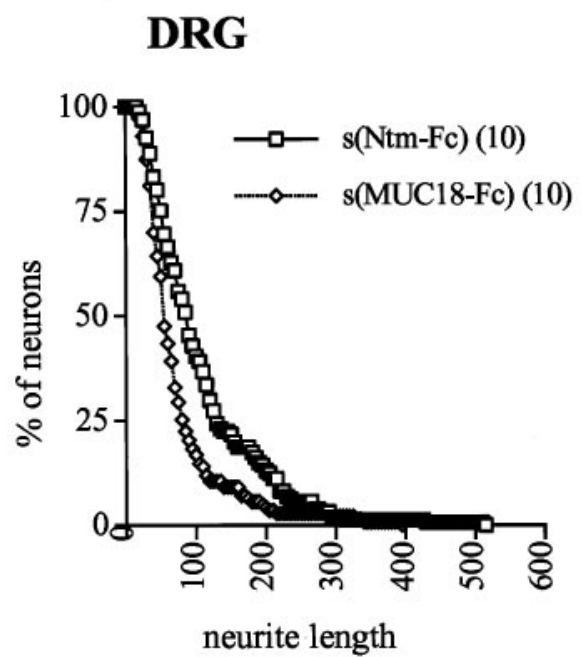

B

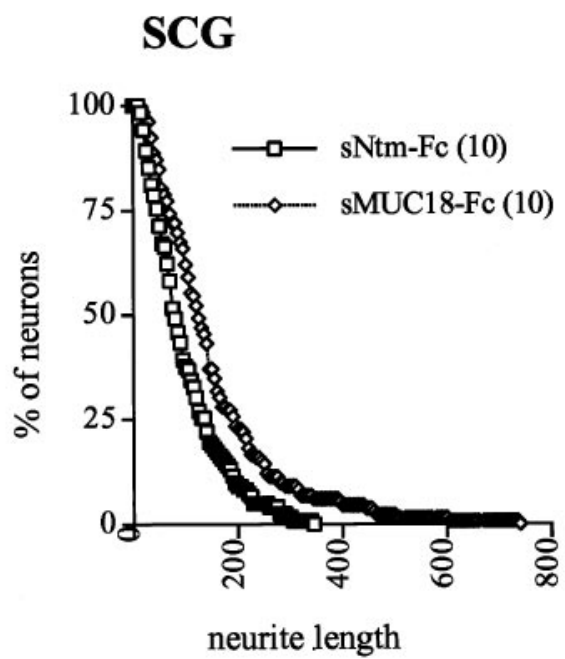

C

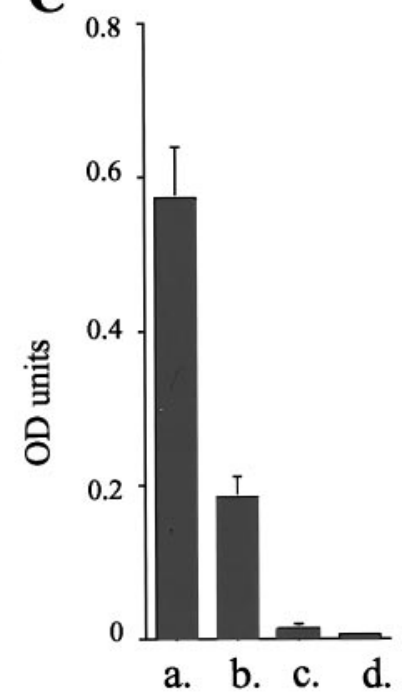

Figure 10. Soluble Ntm-Fc promotes DRG and inhibits SCG neurite outgrowth. Graphs show quantitation of DRG $(A)$ and SCG $(B)$ neurons plated on collagen and laminin substrates, respectively, in the presence of soluble forms of Ntm-Fc or MUC18-Fc. The abscissa corresponds to neurite length (in micrometers), and the ordinate corresponds to the percentage of neurons with neurites greater than a specific length. An ELISA is shown ( $C$ ) in which Ntm-Fc was adsorbed to the plastic dish in buffer alone $(a)$, in culture media with $1 \%$ BSA $(b)$, or in the media but with the plastic precoated with collagen $(c)$ or laminin $(d)$.

activities. The precise signaling pathways involved and the functional consequences of interactions between different family members are important questions for future investigation.

\section{REFERENCES}

Benchimol S, Fuks A, Jothy S, Beauchemin N, Shirota K, Stanners CP (1989) Carcinoembryonic antigen, a human tumor marker functions as an intercellular adhesion molecule. Cell 57:327-334.

Bixby JL, Harris WA (1991) Molecular mechanisms of axon growth and guidance. Annu Rev Cell Biol 7:117-159.

Brewer GJ (1995) Serum-free B27/neurobasal medium supports differentiated growth of neurons from the striatum, substantia nigra, septum, cerebral cortex, cerebellum, and dentate gyrus. J Neurosci Res 42:674-683.

Brieher WM, Yap AS, Gumbiner BM (1996) Lateral dimerization is required for the homophilic binding activity of C-cadherin. J Cell Biol 135:487-496.

Brümmendorf T, Rathjen FG (1993) Axonal glycoproteins with immunoglobulin- and fibronectin type III-related domains in vertebrates: structural features, binding activities, and signal transduction. J Neurochem 61:1207-1219.

Buttiglione M, Revest J-M, Rougon G, Faivre-Sarrailh C (1996) F3 neuronal adhesion molecule controls outgrowth and fasciculation of cerebellar granule cell neurites: a cell-type-specific effect mediated by the Ig-like domains. Mol Cell Neurosci 8:53-69.

Buttiglione M, Revest JM, Pavlou O, Karagogeos D, Furley A, Rougon G, Faivre-Sarrailh C (1998) A functional interaction between the neuronal adhesion molecules TAG-1 and F3 modulates neurite outgrowth and fasciculation of cerebellar granule cells. J Neurosci 18:6853-6870.

Clarke GA, Moss DJ (1997) GP55 inhibits both cell adhesion and growth of neurons, but not non-neuronal cells, via a G-protein-coupled receptor. Eur J Neurosci 9:334-341.

Colamarino SA, Tessier-Lavigne M (1995) The axonal chemoattractant netrin-1 is also a chemorepellent for trochlear motor axons. Cell 81:621-629.

Dodd J, Morton SB, Karagogeos D, Yamamoto M, Jessell TM (1988) Spatial regulation of axonal glycoprotein expression on subsets of embryonic spinal neurons. Neuron 1:105-116.

Doherty P, Williams E, Walsh FS (1995) A soluble chimeric form of the L1 glycoprotein stimulates neurite outgrowth. Neuron 14:57-66.
Drescher U, Bonhoeffer F, Müller BK (1997) The Eph family in retinal axon guidance. Curr Opin Neurobiol 7:75-80.

Durbec P, Gennarini G, Goridis C, Rougon G (1992) A soluble form of the F3 neuronal cell adhesion molecule promotes neurite outgrowth. J Cell Biol 117:877-887.

Evan GI, Lewis GK, Ramsay G, Bishop JM (1985) Isolation of monoclonal-antibodies specific for human c-myc proto-oncogene product. Mol Cell Biol 5:3610-3616.

Faivre-Sarrailh C, Rougon G (1997) Axonal molecules of the immunoglobulin superfamily bearing a GPI anchor: their role in controlling neurite outgrowth. Mol Cell Neurosci 9:109-115.

Felsenfeld DP, Hynes MA, Skoler KM, Furley AJ, Jessell TM (1994) TAG-1 can mediate homophilic binding, but neurite outgrowth on TAG-1 requires an L1-like molecule and beta 1 integrins. Neuron 12:675-690.

Friedrichson T, Kurzchalia TV (1998) Microdomains of GPI-anchored proteins in living cells revealed by crosslinking. Nature 394:802-805.

Galbiati F, Volonte D, Gil O, Zanazzi G, Salzer JL, Sargiacomo M, Parenti M, Okamoto T, Lisanti MP (1998) Expression of caveolins 1 and 2 in differentiating PC12 cells and dorsal root ganglion neurons. Proc Natl Acad Sci USA 95:10257-10262.

Gennarini G, Durbec P, Boned A, Rougon G, Goridis C (1991) Transfected F3/F11 neuronal cell surface protein mediates intercellular adhesion and promotes neurite outgrowth. Neuron 6:595-606.

Henke RC, Seeto GS, Jeffrey PL (1997) Thy-1 and AvGp50 signal transduction complex in the avian nervous system: c-Fyn and $G$ alpha $i$ protein association and activation of signalling pathways. J Neurosci Res 49:655-670.

Klostermann A, Lohrum M, Adams RH, Püschel AW (1998) The chemorepulsive activity of the axonal guidance signal semaphorin D requires dimerization. J Biol Chem 273:7326-7331.

Kolodkin AL, Matthes DJ, Goodman CS (1993) The semaphorin genes encode a family of transmembrane and secreted growth cone guidance molecules. Cell 75:1389-1399.

Koppel AM, Raper JA (1998) Collapsin-1 covalently dimerizes, and dimerization is necessary for collapsing activity. J Biol Chem 273:15708-15713.

Lagenaur C, Lemmon V (1987) An L1-like molecule, the 8D9 antigen, is a potent substrate for neurite extension. Proc Natl Acad Sci USA 84:7753-7757. 
Levitt P (1984) A monoclonal antibody to limbic system neurons. Science 223:299-301.

Luo Y, Raible D, Raper JA (1993) Collapsin: a protein in brain that induces the collapse and paralysis of neuronal growth cones. Cell 75:217-227.

Mann F, Zhukareva V, Pimenta A, Levitt P, Bolz J (1997) Molecular specification of limbic cortical circuits. Soc Neurosci Abstr 23:1699.

Matsunaga M, Hatta K, Nagafuchi A, Takeichi M (1988) Guidance of optic nerve fibers by $\mathrm{N}$-cadherin adhesion molecules. Nature 334:62-64.

Mukhopadhyay G, Doherty P, Walsh FS, Crocker PR, Filbin MT (1994) A novel role for myelin-associated glycoprotein as an inhibitor of axonal regeneration. Neuron 13:757-767.

Nagar B, Overduin M, Ikura M, Rini JM (1996) Structural basis of calcium-induced E-cadherin rigidification and dimerization. Nature 380:360-364.

Pedraza L, Owens GC, Green LAD, Salzer JL (1990) The myelinassociated glycoproteins: membrane disposition, evidence of a novel disulfide linkage between immunoglobulin-like domains, and posttranslational palmitylation. J Cell Biol 111:2651-2661.

Peles E, Nativ M, Lustig M, Grumet M, Schilling J, Martinez R, Plowman GD, Schlessinger J (1997) Identification of a novel contactinassociated transmembrane receptor with multiple domains implicated in protein-protein interactions. EMBO J 16:978-988.

Pimenta AF, Zhukareva V, Barbe MF, Reinoso BS, Grimley C, Henzel W, Fischer I, Levitt P (1995) The limbic system-associated membrane protein is an Ig superfamily member that mediates selective neuronal growth and axon targeting. Neuron 15:287-297.

Pollard JW, Stanners CP (1979) Characterization of cell lines showing growth control isolated from both the wild type and a leucyl-tRNA synthetase mutant of Chinese hamster ovary cells. J Cell Physiol 98:571-586.

Reichardt LF, Tomaselli KJ (1991) Extracellular matrix molecules and their receptors: functions in neural development. Annu Rev Neurosci 14:531-570.

Reichardt LF, Bossy B, Carbonetto S, Curtis ID, Emmett C, Hall DE, Ignatius MJ, Lefcort F, Napolitano E, Neugebauer KM, Tomaselli K (1990) Neuronal receptors that regulate axonal growth. Cold Spring Harbor Symp Quant Biol 55:341-350.

Rosen CL, Lisanti MP, Salzer JL (1992) Expression of a unique sets of GPI-linked proteins by different primary neurons in vitro. J Cell Biol 117:617-627.

Rutishauser U (1993) Adhesion molecules of the nervous system. Curr Opin Neurobiol 3:709-715.

Salzer JL, Colman DR (1989) Mechanisms of cell adhesion in the nervous system: role of the immunoglobulin gene superfamily. Dev Neurosci 11:377-390.

Salzer JL, Rosen CL, Struyk AF (1996) GPI anchored proteins in neural cell adhesion. In: Cell adhesion, Vol. 16, Advances in molecular and cellular biology (Colman DR, ed), pp 193-222. Greenwich, CT: Jai.
Schlessinger J, Ullrich A (1992) Growth factor signaling by receptor tyrosine kinases. Neuron 9:383-391.

Schofield PR, McFarland KC, Hayflick JS, Wilcox JN, Cho TM, Roy S, Lee NM, Loh HH, Seeburg PH (1989) Molecular characterization of a new immunoglobulin superfamily protein with potential roles in opioid binding and cell contact. EMBO J 8:489-495.

Serafini T, Kennedy TE, Galko MJ, Mirzayan C, Jessell TM, TessierLavigne M (1994) The netrins define a family of axon outgrowthpromoting proteins homologous to C. elegans UNC-6. Cell 78:409-424.

Shapiro L, Fannon AM, Kwong PD, Thompson A, Lehmann MS, Grubel G, Legrand JF, Als-Nielsen J, Colman DR, Hendrickson WA (1995) Structural basis of cell-cell adhesion by cadherins. Nature 374:327-337.

Shapiro L, Doyle JP, Hensley P, Colman DR, Hendrickson WA (1996) Crystal structure of the extracellular domain from $\mathrm{P} 0$, the major structural protein of peripheral nerve myelin. Neuron 17:435-449.

Simmons DL (1993) Cloning cell surface molecules by transient expression in mammalian cells. In: Cellular interactions in development: a practical approach (Hartley D, ed), pp 95-126. Oxford: Oxford UP.

Squinto SP, Aldrich TH, Lindsay RM, Morrissey DM, Panayotatos N, Bianco SM, Furth ME, Yancopoulos GD (1990) Identification of functional receptors for ciliary neurotrophic factor on neuronal cell lines and primary neurons. Neuron 5:757-766.

Struyk AF, Canoll PD, Wolfgang MJ, Rosen CL, D'Eustachio P, Salzer JL (1995) Cloning of neurotrimin defines a new subfamily of differentially expressed neural cell adhesion molecules. J Neurosci 15:2141-2156.

Tessier-Lavigne M, Goodman CS (1996) The molecular biology of axon guidance. Science 274:1123-1133.

Tomschy A, Fauser C, Landwehr R, Engel J (1996) Homophilic adhesion of E-cadherin occurs by a co-operative two-step interaction of N-terminal domains. EMBO J 15:3507-3514.

Varma R, Mayor S (1998) GPI-anchored proteins are organized in submicron domains at the cell surface. Nature 394:798-801.

Williams EJ, Doherty P, Turner G, Reid RA, Hemperly JJ, Walsh FS (1992) Calcium influx into neurons can solely account for cell contactdependent neurite outgrowth stimulated by transfected L1. J Cell Biol 119:883-892.

Wilson DJ, Kim DS, Clarke GA, Marshall-Clarke S, Moss DJ (1996) A family of glycoproteins (GP55), which inhibit neurite outgrowth, are members of the Ig superfamily and are related to OBCAM, neurotrimin, LAMP and CEPU-1. J Cell Sci 109:3129-3138.

Zhukareva V, Levitt P (1995) The limbic system-associated membrane protein (LAMP) selectively mediates interactions with specific central neuron populations. Development 121:1161-1172.

Zhukareva V, Chernevskaya N, Pimenta A, Nowycky M, Levitt P (1997) Limbic system-associated membrane protein (LAMP) induces neurite outgrowth and intracellular $\mathrm{Ca}^{2+}$ increase in primary fetal neurons. Mol Cell Neurosci 10:43-55. 